\section{La Révolution française}

Cahiers de l'Institut d'histoire de la Révolution française

$11 \mid 2016$

L'Irlande et la France à l'époque de la République atlantique

\title{
Introduction : L'Irlande et la France à l'époque de la République atlantique : historiographie et nouvelles approches
}

\section{Mathieu Ferradou}

\section{OpenEdition}

\section{Journals}

Édition électronique

URL : http://journals.openedition.org/lrf/1626

DOI : $10.4000 /$ Irf. 7626

ISSN : 2105-2557

\section{Éditeur}

IHMC - Institut d'histoire moderne et contemporaine (UMR 8066)

Édition imprimée

Date de publication : 1 décembre 2016

Référence électronique

Mathieu Ferradou, «Introduction : L'Irlande et la France à l'époque de la République atlantique historiographie et nouvelles approches », La Révolution française [En ligne], 11 | 2016, mis en ligne le 01 décembre 2016, consulté le 30 avril 2019. URL : http://journals.openedition.org//rf/1626 ; DOI : $10.4000 /$ Irf.1626

Ce document a été généré automatiquement le 30 avril 2019.

(c) La Révolution française 


\title{
Introduction : L'Irlande et la France à l'époque de la République atlantique : historiographie et nouvelles approches
}

\author{
Mathieu Ferradou
}

Entre février et juillet 1796, lorsque Theobald Wolfe Tone, arrivé en France depuis les Etats-Unis où il s'était exilé, négocie avec le gouvernement du Directoire au nom des Irlandais Unis ${ }^{1}$ le soutien militaire de la France à une révolte armée en Irlande pour gagner l'indépendance de l'île contre la Grande-Bretagne, il doit faire face à la défiance des officiels français - parmi lesquels le directeur Carnot et le général Clarke² lui-même d'origine irlandaise - quant au républicanisme des Irlandais ${ }^{3}$. Le Directoire est tout particulièrement intéressé par la société secrète des Defenders et, les sachant principalement catholiques, à l'instar de la majorité des Irlandais, il les suppose monarchistes jacobites, sous l'influence de leurs prêtres et de leurs «institutions fanatiques. » Seuls leurs liens avec les presbytériens de l'Ulster seraient une garantie que l'Irlande chercherait à établir une république ${ }^{4}$. Tone reprochait à Clarke son absence de familiarité avec les évènements récents survenus en Irlande, notamment suite à la Révolution française qui y eut une influence décisive ${ }^{5}$, et restait inflexible: «je lui répondis que je n'avais aucun doute que, si nous réussissions, nous établirions une république $^{6}$.» Un peu plus tard, il écrivit :

«Les Defenders sont tous catholiques. Ils ne sont pas menés par leurs prêtres. Au contraire, ces prêtres ont employé tous leurs efforts pour prévenir le défendérisme. [...] Depuis cinq ans le clergé catholique a perdu presque toute son influence sur le peuple, ce qui afflige sincèrement les partisans du gouvernement anglais qui se trouve là privé de son plus puissant instrument pour gouverner les paysans d'Irlande. [...] Ce n'est pas parce qu'ils sont catholiques, mais parce qu'ils sont pauvres et misérables et opprimés que les paysans d'Irlande sont des Defenders. [...] En ce qui concerne la royauté, personne en Irlande ne la soutiendrait un seul 
instant. En cas de révolution là-bas, elle n'aboutira certainement pas à un gouvernement royal ${ }^{7}$.

2 Pourtant, l'insistance de Tone ne suffit pas à mettre fin aux préjugés des Français ${ }^{8}$. Lazare Hoche, lorsqu'il fut nommé général en chef de l'expédition d'Irlande, partageait ces doutes. A ses yeux, la France devait aider l'Irlande (catholique) à sortir du royalisme pour aller vers le républicanisme :

Nul doute d'ailleurs que si les Membres du Comité catholique et ceux de l'assemblée de l'Union des Deffenders se rassemblent, on ne doive les considérer comme les véritables Représentants de la Nation. [...] Il faudra [...] se conduire avec la loyauté, la générosité qui caractérisent la Nation française ; chercher toujours à concilier les Insurgents qui pourraient se diviser pour des motifs quelconques et conduire les esprits vers le gouvernement républicain.

Il est également important de connaître quelle conduite l'officier Général commandant doit tenir si l'Irlande, bien qu'en se détachant de l'Angleterre, conserve pour le Gouvernement Monarchique un attachement tel que l'assemblée des Députés adopte la Royauté et donne à la Nation Irlandaise un chef pris dans son

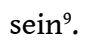

3 Ainsi, dès le moment fondateur du républicanisme irlandais, celui-ci était mis en doute par la France. Le but politique de l'expédition n'était pas forcément très clairement défini dans les esprits de ses responsables : gêner l'Angleterre assurément; mais quant à la possibilité d'aider à l'instauration d'une république irlandaise, le flou persistait ${ }^{10}$.

L'échec de 1796, avec le désastre de la baie de Bantry, puis celui de la « Rébellion » de 1798 ${ }^{11}$ avec l'arrivée, trop tard, de l'expédition de Humbert dans le Connaught, l'acte d'Union entre l'Angleterre et l'Irlande, en 1800-1801 ${ }^{12}$, et, enfin, l'échec de la révolte de Robert Emmet en $1803^{13}$ semblèrent donner raison à ceux qui doutaient du républicanisme des Irlandais et suscitèrent une interprétation de 1798 comme l'expression d'un catholicisme fanatique de la part des Irlandais. L'histoire de l'Irlande au XIX ${ }^{\mathrm{e}}$ et au XX $\mathrm{XX}^{\mathrm{e}}$ siècle semble confirmer cette vision. Le combat de l'Irlande serait ainsi avant tout celui du nationalisme catholique, la "république " n'étant que la forme circonstancielle qu'il a pris à un moment, dans sa forme séparatiste, sous l'impulsion des Irlandais Unis, républicains à contrecœur et tardifs. Son caractère protéiforme - impérial, monarchique, républicain après 1798 tendrait à conforter cette idée d'un "républicanisme ambigu ${ }^{14}$ ». De plus, l'échec de 1798 a aussi été l'échec d'une république inclusive et multiconfessionnelle, polarisant la société irlandaise entre catholiques nationalistes et protestants (y compris presbytériens) unionistes en réaction à la menace d'une Irlande indépendante catholique. Les termes clés sont ainsi dramatiquement posés, sujets à confusions et à querelles historiographiques: indépendance, nation, république, révolution, violence. Et la question religieuse vient troubler le sens et la portée de chacun de ces termes.

\section{Aux origines du républicanisme irlandais : un écran mémoriel et historiographique à franchir}

5 Ainsi, mort-née une première fois en 1798, puis au cours d'une insurrection en 1916, proclamée à nouveau en 1919, formellement déclarée en 1949 dans un acte aujourd'hui largement méconnu (qui lui a pourtant valu, ironie du vocabulaire, l'expulsion du Commonwealth britannique dont le règlement interdisait qu'une république en soit membre), question centrale au cœur de deux guerres civiles (1922-1923 et 1969-1998), la 
république est bien un nœud idéologique, mémoriel et historique autour duquel se cristallisent multiples interprétations et conflits.

6 Dans cette optique, la proclamation de la République irlandaise lors de l'insurrection de Pâques 1916 semble être un accident de l'histoire. Pourtant, si la mémoire a retenu 1916, cette date s'inscrit dans une séquence plus longue, appelée "Révolution irlandaise » (1913-1923). Les questions liées à la nation, l'indépendance, la révolution avec comme articulation l'idée de république se posèrent à nouveau ${ }^{15}$. De plus, le caractère accidentel de la république irlandaise, loin d'être exceptionnel, est en fait partagé par les républiques américaine et française. En Irlande, comme en France ou aux Etats-Unis, la république est loin d'aller de soi ce d'autant plus qu'avec la Révolution irlandaise puis les «Troubles » (1969-1998), le terme de « républicain » est porté par le Sinn Féin, le Fianna Fáil, l'IRA (Irish Republican Army) puis de la Provisional IRA, branche dissidente prétendant incarner la continuité républicaine. Le républicanisme est ainsi associé au recours à la violence armée dans la sphère politique, au nom de l'indépendantisme et du nationalisme, et en opposition à la démocratie et au constitutionnalisme. Il serait ainsi une idéologie incohérente, dont le point commun entre tous les mouvements qui s'en réclament est la conviction d'incarner la légitimité - même, et surtout, s'ils sont minoritaires - face au légal (le constitutionalisme de la démocratie libérale venue d'Angleterre) qui est synonyme de compromission avec l'ancien ordre colonial ${ }^{16}$. En écrire l'histoire des origines dans les années 1790, tout particulièrement dans les années 1980 et 1990, était donc un exercice particulièrement périlleux et le contexte influença les historiens irlandais, ainsi que Thomas Bartlett l'a rappelé tout en soulignant la portée toujours considérable dans le paysage politique actuel des mots qui servent de concepts pour analyser la période : radicalisation, insurrection, conspiration ${ }^{17}$.

7 Le centenaire de 2016 aura permis une immense production historique en Irlande, et une volonté de la part de très nombreux Irlandais de s'interroger sur ce que signifie le mot « république ». Pourtant, malgré cette immense demande publique, très peu d'historiens ont pu faire valoir, au cours des commémorations, que la république qui semble soudain émerger en 1916 était en réalité une résurgence, un re-jeu : la célèbre proclamation de la république de 1916 avait eu des antécédents avec celle des Fenians en 1867, celle de Robert Emmet en 1803 et ou celles rédigées par les officiels français (et, derrière eux, des Irlandais) lors des deux tentatives de 1796 et 1798, elles-mêmes puisant à la fois aux sources atlantiques de la Déclaration des Droits de l'Homme et de la Déclaration d'Indépendance des Etats-Unis d'Amérique ${ }^{18}$. Les fils de l'indépendance, du nationalisme, de la révolution et de la république s'étaient déjà noués dans la décennie révolutionnaire, et ce d'autant plus tragiquement que cette période fut pour l'Irlande, en renversant le mot de Robespierre, celle de révolutionnaires sans révolution.

C'est cet autre fil, quelque peu oublié, que la journée d'étude organisée à l'Institut d'histoire de la Révolution française (IHRF) avec le soutien de l'Institut d'histoire moderne et contemporaine (IHMC) sur « l'Irlande et la France à l'époque de la République atlantique " se proposait de remonter en réunissant historiens américains, irlandais, anglais et français ${ }^{19}$. L'objectif était de rouvrir le chantier historiographique de la décennie 1790 en Irlande en la plaçant dans un contexte plus large, à la fois géographique, en explorant ses liens privilégiés avec la France révolutionnaire et en ouvrant l'horizon vers l'Atlantique, mais également en agrandissant la focale chronologique pour replacer cette décennie dans la période de l'Atlantique des révolutions de 1763 (et même avant, depuis la Guerre civile anglaise !) jusqu'en 1848. 
Cette journée d'étude s'inscrivait donc dans deux perspectives historiographiques particulièrement fécondes: la première, celle de l'histoire globale/connectée, qui réexplore la dimension atlantique voire globale de «l'âge des révolutions ${ }^{20} »$; la seconde, celle des études sur le républicanisme ${ }^{21}$. Ces deux approches ont été conciliées dans le concept de « République atlantique ${ }^{22}$.» Celui-ci implique que les républiques nées dans la «Révolution atlantique » se sont nourries entre elles, dans un jeu de miroir entre modèle et rejet. Replacer l'Irlande dans cette chaîne de la «République atlantique " permet de mieux interroger le passé inaccompli : la république a été souhaitée, pensée, voulue en Irlande mais n'est pas advenue. Pourtant, elle a continué d'irriguer l'histoire souterraine $\mathrm{du} \mathrm{XIX}^{\mathrm{e}}$ siècle pour resurgir au XX $\mathrm{XX}^{\mathrm{e}}$ siècle ${ }^{23}$. Il s'agissait donc de tenter de retrouver ce passé inaccompli pour essayer d'identifier la constellation des multiples significations et espoirs dont la république a été le catalyseur, moteur de l'action de ces nombreux Irlandais qui circulèrent dans l'espace atlantique pour la faire advenir.

\section{L'historiographie de la « république inachevée » irlandaise}

De quoi 1798 a-t-il donc été le nom ? S'agissait-il d'une jacquerie paysanne, d'une révolte nationaliste, d'une guerre d'indépendance perdue, d'une chouannerie, d'une rébellion, ou d'une guerre civile ${ }^{24}$ ? Répondre à cette question suppose de remonter l'historiographie de la «Rébellion», pour en analyser les interprétations, et identifier les écrans historiographiques sous lesquels la république non-advenue a été enfouie ${ }^{25}$.

11 Parmi les ouvrages publiés dans l'immédiat après-1798, celui de Richard Musgrave, Memoirs of the Different Rebellions in Ireland..., publié à Dublin en 1801 a eu une influence décisive pour imposer l'idée d'un "complot papiste» contre les protestants, reprenant ainsi la propagande gouvernementale, se nourrissant d'une longue mémoire protestante de peur vis-à-vis des catholiques depuis la révolte de 1641, imposant ainsi une lecture confessionnelle de l'évènement. Les réponses libérales à Musgrave insistèrent sur l'idée que les insurgés de 1798 l'avaient été "malgré-eux", acteurs passifs de leur histoire forcés de se soulever contre l'oppression menée par le gouvernement assisté de l'Ordre d'Orange. Cette interprétation convenait à la fois au gouvernement irlandais, chargé de la répression de la « rébellion » et de faire accepter l'acte d'Union en 1800, ainsi qu'à l'Eglise catholique qui se dédouanait par là même de toute participation dans la "rébellion » et dénigrait les prêtres qui y avaient pris part en les accusant d'être des «alcooliques, excommuniés, les déjections de l'Eglise ${ }^{26}$.» Tous deux pouvaient ainsi rejeter la faute de la « Rébellion » sur le « jacobinisme » importé de France. Dans les années 1820-1840, ainsi que Laurent Colantonio l'a montré, Daniel O'Connell, le "Libérateur ", fit campagne en faveur de l'émancipation des catholiques tout en organisant l'oubli de la participation des Irlandais catholiques à la « Rébellion » de 1798 ou en accusant les presbytériens d'en avoir été responsables, devenant ainsi responsable du lien entre catholicisme et nationalisme en Irlande. Car si O'Connell professait lui aussi un nationalisme inclusif, il rejetait le projet républicain des Irlandais Unis, associés à l'échec de la violence de 1798, et préférait le recours aux "meetings de masse » dans un lien charismatique entre lui et le peuple, lien qui fascina les républicains français. Mais, à la république, O'Connell préférait la démocratie dans une Irlande post-Union intégrée au projet impérial britannique ${ }^{27}$. Un premier écran était ainsi dressé face à l'expérience républicaine irlandaise et son échec. 
12 Les historiens de la seconde moitié du XIX ${ }^{e}$ siècle expliquèrent la Révolte par l'échec de la politique anglaise en Irlande. Richard R. Madden a compilé la vie de 73 Irlandais Unis dans une optique hagiographique, passant sous silence l'influence de la Révolution française, et blâmant le gouvernement anglais pour les avoir forcés à utiliser la violence en ignorant leur «patriotisme ${ }^{28}$.» Pour les libéraux unionistes, cet échec venait soit du fait de l'incapacité des Irlandais à assimiler les avancées anglaises ${ }^{29}$, soit du fait d'une mauvaise stratégie du gouvernement anglais ${ }^{30}$. Dans les années 1920, immédiatement après l'indépendance de l'Irlande, Daniel Corkery relança le débat sur le statut colonial de l'Irlande en défendant l'idée que l'Irlande était alors divisée en deux sociétés parallèles : d'un côté, la société de l'Ascendancy, protestante, anglophone, constituée des propriétaires terriens (environ 5000 ) souvent absents, contrôlant le Parlement de Dublin; de l'autre, l'«Irlande cachée» (concept qui marqua durablement l'historiographie), c'est-à-dire la société gaélique et catholique, rurale, formée de petits paysans non-propriétaires vivant dans la misère. Entre les deux populations, les «lois pénales", votées par le Parlement irlandais entre 1688 et 1724, interdisaient aux catholiques de posséder des terres, un cheval, une arme, d'ouvrir des écoles catholiques ${ }^{31}$. Corkery dressait un tableau d'une Ascendancy à la culture décadente (celle de la « richesse sans le raffinement, du pouvoir sans la responsabilité ») qu'il opposait à la culture autonome et riche de la poésie et de la musique gaéliques nourrissant, entre autres, un jacobinisme synonyme de mécontentement envers le gouvernement et la classe des "planteurs protestants étrangers ${ }^{32}$.

13 L'« école révisionniste » irlandaise, inspirée de l'école des Annales, s'est développée à partir des années 1930-1940 33 . Ces historiens s'étaient donnés pour axe programmatique d'appliquer à l'histoire les méthodes scientifiques de la recherche, la critique des sources, en opposition à une histoire populaire nationaliste (ou même unioniste) dominante, notamment depuis le moment républicain révolutionnaire de 1916-1922. Ils offrirent alors une vision nuancée de l'Irlande au XVIII e siècle, Maureen Wall montrant que les lois pénales n'empêchèrent pas le développement d'une riche "classe marchande" catholique concentrée dans les ports irlandais et sur la façade atlantique du Continent, Louis M. Cullen insistant sur son décollage économique et sa croissance démographique qui mettait à mal l'image d'une Irlande miséreuse ${ }^{34}$. James Camlin Beckett insista sur la prospérité et le progrès que représentait l'Irlande de l'Ascendancy, caractérisant le XVIII ${ }^{\mathrm{e}}$ siècle irlandais comme la plus longue "période de paix intérieure et de sécurité » de l'histoire de l'île. Pour lui, le libéralisme et la tolérance religieuse, essentiellement protestants, étaient en marche dans le pays avant d'être balayés par les évènements dramatiques des années $1790^{35}$. Cette vision du XVIII ${ }^{e}$ siècle a culminé dans le volume de la New History of Ireland, publié en 1986, et qui parut presque immédiatement daté36.

Dans la lignée de l'école révisionniste, et suite au regain d'intérêt pour le radicalisme anglais avec Edward P. Thompson et Eric Hobsbawm, Marianne Elliott a publié en 1982 son ouvrage fondamental, Partners in Revolution, dans lequel elle analysait les projets des Irlandais Unis en lien avec la France du Directoire ${ }^{37}$. Nancy Curtin, quant à elle, a examiné leur composition et leurs projets ${ }^{38}$. Toutes deux concluaient que les Irlandais Unis étaient des républicains classiques et n'étaient devenus des révolutionnaires que tardivement, vers 1794-1795 face à la répression du gouvernement anglo-irlandais. Leur projet politique était volontairement flou afin de ne pas heurter leurs alliés catholiques, les Defenders. D'ailleurs, elles voyaient dans cette alliance la cause de l'explosion "sectaire " de violence en 1798, les Defenders étant motivés par une revanche sociale et religieuse 
que les Irlandais Unis, jouant les apprentis-sorciers, ne parvinrent pas à contenir, tandis que l'alliance française apportait aux Irlandais-Unis une force militaire sans commune mesure avec leur véritable représentativité en Irlande ${ }^{39}$.

Avec le bicentenaire de la fondation de la société des Irlandais Unis (en 1991) mais surtout celui de 1798 et, dans la lignée du post-colonialisme, le débat s'est structuré autour du statut de l'Irlande entre modèle colonial et modèle d'ancien régime ${ }^{40}$. Le modèle de l'Irlande d'ancien régime replace les divisions religieuses au cœur de la société et de la politique irlandaises mais pour mieux en souligner le relatif bon fonctionnement grâce à un ensemble de freins sociaux et idéologiques. Les historiens qui proposent cette analyse remarquent que les lois pénales ne sont pas un cas unique, soulignant même que la discrimination religieuse est une pratique ordinaire de l'Europe du XVIII ${ }^{e}$ siècle ${ }^{41}$. Dans une volonté « contre-téléologique », les historiens partisans du modèle de l'ancien régime mettent l'accent sur le rôle des contingences, refusant de voir des « origines » à long terme derrière les évènements de 1798, reprenant ainsi l'idée du XVIII ${ }^{e}$ siècle tranquille. Pour Nicholas Canny, les révoltes en Irlande en 1641, 1690 et 1798, "dans une communauté relativement harmonieuse et ordonnée, qui jouissait d'une prospérité modeste en tant que partenaire globalement satisfait à l'intérieur d'une juridiction britannique plus large " sont dues à "des accidents, ou aux excès de l'Etat, ou à une intervention étrangère ${ }^{42}$. "

16 Le modèle colonial met au contraire l'accent sur l'histoire de conquêtes et d'expropriations qu'a subi l'Irlande. La société irlandaise serait caractérisée par les divisions politiques, culturelles et religieuses entre les colonisateurs et les colonisés. Les coutumes de l'élite anglo-irlandaise comme la culture du duel et de l'alcool, le conservatisme religieux de la théologie anglicane et l'absence de tradition musicale seraient alors autant de caractéristiques d'une classe dirigeante coloniale. Ce modèle semble être l'héritier de l'historiographie nationaliste qui affirmait que les catholiques irlandais « étaient peu respectueux des lois car ils ne connaissaient la loi que comme ennemie ${ }^{43}$. » Le fait que les catholiques, qui représentaient environ $70 \%$ de la population de l'Irlande, ne possédaient que $5 \%$ des terres en 1778 suffit à rappeler leur situation d'infériorité légale. La « Rébellion » de 1798 n'apparaît plus alors comme une occurrence étrangère mais bien comme le résultat d'une oppression.

Autre questionnement : la place de l'Irlande dans la chaîne des révolutions atlantiques. James Camlin Beckett explique la rupture de la décennie 1790 par la Révolution française : " jusqu'à l'importation des idées françaises à la toute fin de la période, il n'y avait aucun signe d'aucune manœuvre politique que ce soit dirigée contre le système de gouvernement ${ }^{44}$. » Sean Connolly, à sa suite, réaffirme que «les tensions des années 1790 ne doivent pas être lues à rebours pour caractériser toute la période post-williamite [à partir de 1690] ${ }^{45}$. » Notant la continuité des pratiques politiques et du système politique tout entier avant et après 1798, il pose alors la question : « de ce point de vue, il devient possible de se demander si ce ne sont pas les évènements des années 1790 qui doivent être vus comme exceptionnels, le reflet local d'une crise internationale sans précédent, plutôt que comme le moment qui définirait l'histoire irlandaise du XVIII ${ }^{e}$ siècle ${ }^{46}$. $»$ Dans cette perspective, la Révolution américaine et surtout la Révolution française jouent un rôle déterminant. Kevin Whelan considère, au contraire, que l'historiographie a trop mis l'accent sur le rôle de la Révolution française en Irlande au détriment de celui la Révolution américaine, surestimant ainsi la rupture entre les années 1780 et les années 1790. Il considère que non seulement cette lecture surestime « le poids de la Révolution 
française comme explication du radicalisme irlandais dans les années 1790, mais cela pose également la question de savoir pourquoi l'Irlande, et non pas l'Ecosse, le Pays de Galles ou l'Angleterre (qui étaient au moins aussi exposés à l'influence française), a fait l'expérience d'un effondrement aussi massif dans cette décennie ${ }^{47}$. "

\section{Le contexte de guerre : synergies républicaines franco-irlandaises}

Cette journée d'étude avait donc l'ambition de contribuer à ce débat. Pour cela, Thomas Bartlett a attiré l'attention, en ouverture, sur un aspect crucial de cette période pour mieux appréhender ses dynamiques : la guerre entre la France et l'Angleterre à partir de 1793. Avec les French Wars (1793-1815), épisode ultime de la « Seconde guerre de Cent Ans ${ }^{48}$ ", la France et l'Angleterre s'opposent dans une lutte doublement à mort: elle détermine laquelle des deux puissances sera la première dans la mondialisation, et surtout la France joue la survie de son nouveau régime. De là, la question de la « guerre totale»dont le concept a été appliqué par David Bell à la France révolutionnaire ${ }^{49}$, suscitant une controverse $\mathrm{e}^{50}$, et auquel un collectif d'historiens a répondu, interrogeant les liens entre république et guerre ${ }^{51}$. Il apparait en effet que pour la République, la guerre ne peut n'être qu' " à outrance » puisque son existence même passe par la reconnaissance de son indépendance et donc de sa souveraineté par les autres puissances ${ }^{52}$.

Dans ce contexte, l'Irlande joue un double rôle. Elle est tout d'abord un enjeu de taille dans la lutte entre les deux pays, notamment pour les immenses ressources qu'elle recèle (en terres, en bétail, en céréales, en hommes). Thomas Bartlett a pu souligner que la mobilisation en hommes en Irlande dans les années 1790 - entre 20 et $25 \%$ de la cohorte des hommes d'une génération - équivalait à celle observée pendant la Première Guerre mondiale tandis qu'un quart environ des matelots de la flotte anglaise sont irlandais ${ }^{53}$. Tous les émissaires irlandais ne cessent de mettre l'accent sur ce point auprès des gouvernements français successifs : priver l'Angleterre de l'Irlande c'est la priver de sa puissance.

De plus, cette situation de "guerre à outrance " entre les deux pays a pour autre conséquence de transformer toute demande de réforme en sédition potentielle. A l'instar des « radicaux » anglais, les Irlandais Unis étaient initialement « constitutionnalistes » et non révolutionnaires puisqu'ils demandaient une réforme du parlement, même s'ils allaient plus loin que d'autres "patriotes » en demandant qu'y soient représentés les catholiques. Il s'agissait pour eux avant tout de « recouvrer » des libertés malmenées par la corruption politique pourtant inscrites dans la « Constitution » depuis le règne d'Alfred et dont l'Irlande, dans une fiction théorique formée au XVII siècle, avait bénéficié depuis le XIII ${ }^{e}$ siècle lorsqu'elle avait reçu sa propre Magna Carta et son propre parlement. En cela, les Irlandais Unis s'inscrivaient dans la double tradition du constitutionnalisme britannique et $\mathrm{du}$ républicanisme classique qui avait d'abord trouvé une première expression en Irlande avec le célèbre pamphlet de William Molyneux, The Case of Ireland's Being Bound by Acts of Parliament in England, Stated, publié en 1698 à Dublin. Molyneux prétendait que l'Irlande n'était pas une colonie mais un royaume à part entière, dont le peuple avait volontairement confié la couronne à Henri II d'Angleterre dans un pacte lockéen typique. Mais il ne parvenait pas à résoudre la tension entre la prétention de l'Irlande à former un royaume indépendant et la situation coloniale d'une élite anglo- 
irlandaise dont il prétendait qu'elle était virtuellement le peuple irlandais. Ce «nationalisme protestant irlandais» fut métamorphosé au moment de la Révolution américaine qui donna naissance au mouvement des Volontaires, articulant ces deux langages avec un troisième : le patriotisme dans son incarnation du citoyen en armes. En combinant mobilisation politique et menace armée, les Volontaires exigèrent une autonomie législative vis-à-vis de Londres en 1782 au nom d'un quatrième langage, celui du libéralisme commercial, contre les restrictions imposées par l'Angleterre à l'Irlande. Cette « révolution de 1782 » buta cependant à nouveau sur la contradiction essentielle entre les différentes traditions qu'elle mobilisait : la division confessionnelle de la société. Car depuis le XVII ${ }^{\mathrm{e}}$ siècle, les protestants britanniques et irlandais opposaient au « despotisme catholique » et à son «fanatisme romain »- visions qui s'exprimaient dans le terme de "papistes" utilisé pour désigner les catholiques - la "liberté anglaise ", associée à la liberté protestante, ce qui justifiait l'exclusion des catholiques de la citoyenneté et de tous les attributs associés. Le patriotisme anglo-irlandais (protestant) aboutissait ainsi à une aporie: le rejet des catholiques, et donc de la majorité des Irlandais, de cette construction théorique et idéologique. Or, si les droits des Irlandais trouvaient leur origine dans la trans-plantation du protestantisme et du constitutionalisme britanniques en Irlande, comment justifier la demande de l'indépendance et de la souveraineté irlandaises? Si la «Révolution» de 1778-1782 aboutit, principalement sous la pression de Londres, soucieux de garantir la loyauté des catholiques irlandais dans un contexte de guerre avec les puissances catholiques française et espagnole, à quelques mesures d'abolition des lois pénales (notamment le droit de posséder la terre), les catholiques furent maintenus hors de la Cité. Les Volontaires euxmêmes n'intégrèrent les catholiques dans leurs rangs que de manière très minoritaire. La «Révolution de 1782 » restait inachevée, et une ambiguïté persistait sur le sort des catholiques ${ }^{54}$.

La Révolution française fait exploser tous les cadres mentaux qui prévalaient jusqu'alors, remettant fondamentalement en cause le dogme de la supériorité protestante et reposant la question des droits naturels, mais cette fois-ci pour l'ensemble des Irlandais, y compris - et surtout - pour les catholiques. En renversant une monarchie vieille de 1400 ans, en proclamant la liberté de culte dans la Déclaration des droits de l'Homme et du Citoyen, la France, cette "fille ainée de l'Eglise", montre dans un coup de tonnerre que les catholiques ne sont plus incapaces libertatis. Tone ne manque pas de le comprendre et il salue la Révolution française comme "l'étoile du matin de la liberté " pour l'Irlande ${ }^{55}$, expression qui donne son titre au journal des Irlandais Unis, The Morning Star, publié à Belfast à partir de 1792. Lorsque les Irlandais Unis sont fondés entre l'été et l'automne 1791 à Belfast puis à Dublin, leur mot d'ordre est « d'établir une Société Unie de la Nation Irlandaise, de faire de tous les Irlandais des Citoyens, de tous les Citoyens des Irlandais ${ }^{56}$. » En privé, Tone écrivait que c'était là le moyen d'obtenir l'indépendance de l'Irlande ${ }^{57}$. En renouant ainsi patriotisme, constitutionalisme, droits naturels et indépendance, les Irlandais Unis dépassaient l'aporie de 1782 (que Tone avait parfaitement identifié dans son célèbre pamphlet An Argument on Behalf of the Catholics of Ireland, publié en août 1791, au retentissement considérable ${ }^{58}$ ) et réintégraient une tradition républicaine souterraine transmise depuis les auteurs du milieu du XVII ${ }^{\mathrm{e}}$ siècle notamment par les presbytériens d'Irlande du Nord, à qui Tone adressait son pamphlet, et par des figures telles John Toland, Robert Molesworth ou Charles Lucas ${ }^{59}$. 

s'accommoder d'une monarchie, d'autant que c'était là la justification de la perfection de la "Constitution » anglaise qui équilibrait monarchie, aristocratie et démocratie dans son gouvernement mixte de King, Lords and Commons. Il s'agissait donc, pour les Irlandais Unis, de recouvrer les libertés garanties par la Constitution, mais pour tous, pourvu que le Parlement irlandais et la monarchie anglaise puissent les garantir. Ils adoptèrent ainsi le langage de la réforme et du constitutionalisme. Il en fut de même pour le Comité catholique (dont Tone était le secrétaire en 1791-1793) qui professait sa loyauté auprès du roi d'Angleterre, lui demandant de satisfaire leurs doléances. dissipa également ces illusions, et ce n'est pas un hasard si c'est un Irlandais, Edmund Burke qui, le premier, le comprit et l'énonça dans ses Reflections on the Revolution of France ${ }^{61}$, publiées en novembre 1790. Burke, né et ayant grandi en Irlande dans une famille mixte (sa mère était catholique), identifia parfaitement la subversion que représentaient les idées révolutionnaires françaises pour l'Angleterre: en proclamant le dogme de l'égalité de tous, la Déclaration, appliquée en Irlande, remettait en cause le gouvernement anglo-irlandais et impliquait à terme une séparation entre les deux îles, perspective insupportable pour cet impérialiste britannique ${ }^{62}$ qui voulait au contraire intégrer plus complètement l'Irlande dans le « système-monde britannique ${ }^{63}$. » En réponse, Burke tenta de résoudre la contradiction entre les différentes traditions du constitutionnalisme, $d u$ républicanisme classique et de la supériorité protestante d'une manière opposée à celle des Irlandais Unis, en proposant le concept de «représentation virtuelle»: le peuple devait se contenter d'être représenté par une élite de propriétaires terriens, mieux qualifiée car vertueuse, impliquant ainsi le principe héréditaire, seul garant de la stabilité de l'ordre social ${ }^{64}$. En d'autres termes, Burke tentait à sa manière de réconcilier le républicanisme classique - whig - dont il se réclamait avec l'exclusion de la majorité de la population du pouvoir politique. C'est pourquoi il promouvait également l'idée de tolérance religieuse et militait en faveur de la suppression des lois pénales, méprisant l'intolérance de l'Ascendancy en Irlande. Pour consolider le lien entre l'Irlande et l'Angleterre, lien qui garantissait à la première la participation au projet impérial de la seconde ainsi que le bénéfice d'une intégration au centre éclairé métropolitain, il était nécessaire d'attacher les catholiques à la "Constitution» britannique, en intégrant progressivement les plus fortunés - les plus éclairés - d'entre eux au Parlement où ils participeraient de cette «représentation virtuelle» de la nation irlandaise puisque les anciennes familles aristocratiques catholiques incarnaient la tradition en Irlande, seule garante de l'ordre dans une société policée. Ainsi appliqué à l'Irlande, l'argumentaire de Burke était à la fois conservateur et révolutionnaire ; il remettait en cause et défendait la domination anglo-irlandaise protestante ${ }^{65}$. Cette vision inspira en partie William Pitt en 1792-1793 lorsqu'il accorda aux catholiques irlandais le droit de vote - mais pas celui d'être élu - au Parlement ${ }^{66}$.

Nul hasard également qu'un proche de Burke, Thomas Hussey, alors chapelain de l'ambassadeur d'Espagne à Londres, exprima le premier - dès août 1790 ! - la crainte d'une circulation des idées françaises en Irlande, leur attribuant la responsabilité du changement d'attitude des catholiques irlandais vis-à-vis de leur clergé, en les qualifiant de «maladie française ${ }^{67}$.» C'est ce discours «burkéen» d'hostilité à la Révolution française et au républicanisme partagé - ne serait-ce qu'aux yeux de ses opposants - que Pascal Dupuy a exploré dans sa contribution sur la propagande iconographique née de 
cette construction en repoussoir d'un républicanisme révolutionnaire " jacobin », forgée dès la Révolution américaine : la République, dans ses incarnations d'abord américaine puis française, y est érigée en contre-modèle anarchique, violent et misérable face aux libertés, au règne de la loi et à l'ordre social anglais ${ }^{68}$.

Cette opposition entre deux modèles fut renforcée par la collusion avérée et précoce entre certains Irlandais et la France républicaine, qui s'exprima dès l'automnehiver 1792-1793 à travers la société des Anglais, Ecossais et Irlandais à Paris dans des projets d'insurrection aidés par la France, en même temps que les rapprochements entre les catholiques et les presbytériens, entre les Irlandais Unis et les Defenders, contribuèrent à augmenter les tensions entre les deux pays. Ceci doit permettre d'inverser la chronologie habituellement admise: les Irlandais et la France ne se rapprochèrent pas suite à la guerre, mais c'est ce rapprochement qui contribua à déclencher la guerre ${ }^{69}$. La chute du roi en août 1792 puis son exécution en janvier 1793 furent d'ailleurs le prétexte que l'Angleterre attendait pour provoquer une guerre. La républicanisation du régime français transformait le sens du mot république, en en faisant "l'antonyme de la monarchie ${ }^{70}$ ", entrainant la rupture des liens diplomatiques entre les deux pays ce qui, en retour, conduisait à la guerre. Dans ce contexte, Rachel Rogers a étudié comment, à Paris, cette société qui gravitait autour de Thomas Paine, se constitua en Société des Amis des Droits de l'Homme (SADH) et ses membres, ayant choisi la France comme lieu de résidence, collaborèrent à plusieurs projets, montrant par là le caractère cosmopolite du patriotisme de la Révolution républicaine atlantique où les identités nationales étaient en flux et se définissaient avant tout politiquement. La décennie 1790 fut donc celle d'un affrontement entre deux conceptions du patriotisme, d'où une nouvelle conception de la nationalité émergea entre la France et l'Angleterre ${ }^{71}$. Elle fut également celle d'une lutte idéologique qui fixa le sens des mots au profit des vainqueurs, la définition de la nationalité devenant synonyme de loyalisme héréditaire ${ }^{72}$.

Ainsi, la Révolution française obligea les Irlandais Unis à abandonner (au moins initialement) le langage de la supériorité protestante et à réarticuler les autres langages constitutionnel, patriotique, droits naturels et républicanisme classique - dans un républicanisme inclusif et internationaliste ${ }^{73}$. Dès lors, le projet républicain des Irlandais Unis, s'il pouvait sembler compatible en théorie avec la monarchie anglaise, remettait fondamentalement en cause, en tant que projet d'« indépendance ", c'est-à-dire de liberté de l'ensemble des Irlandais dans un régime réformé, à la fois la domination de l' Ascendancy et le lien entre les deux royaumes anglais et irlandais. La demande de réforme parlementaire, même exprimé dans le langage du constitutionnalisme, ne pouvait donc être reçue par l'Ascendancy protestante et par le gouvernement anglo-irlandais que comme une remise en cause radicale de leur domination. La Révolution française puis la guerre contre la République française, révélèrent cette antinomie entre le projet républicain des Irlandais Unis et le projet traditionnel burkéen du gouvernement de Pitt, qui s'allia donc au projet exclusif et colonial de l'Ascendancy dans une répression systématique dès l'hiver 1792. En d'autres termes, pour que le potentiel révolutionnaire sous-jacent du projet des Irlandais Unis soit dévoilé, il fallait d'abord que la contrerévolution se manifeste ${ }^{74}$. 


\section{L'Irlande, « lîle des esclaves ${ }^{75}$ » ou la cristallisation des questions révolutionnaires et républicaines}

27 La Révolution française apparait donc davantage comme le déclencheur des tensions et le révélateur de langages de contestation sous-jacents en Irlande dont elle change les signifiés. C'est cette lecture dialectique, et évolutive en fonction des contextes, des tensions qui sont au cœur de la société irlandaise du XVIII ${ }^{\mathrm{e}}$ siècle qui permet de mieux saisir comment le républicanisme irlandais s'inscrit à la fois dans une série d'héritages multiples et parfois contradictoires et dans un projet de ré-invention du futur qui puisse concilier ou dépasser ces contradictions.

Dès lors, ainsi que le note Ian McBride, les deux modèles historiographiques de l'ancien régime et de la société coloniale de l'Irlande du XVIII ${ }^{e}$ siècle ne sont pas exclusifs et doivent au contraire être combinés afin de mieux comprendre comment les multiples tensions de la société irlandaise du XVIII siècle sont révélées, catalysées et transformées par les révolutions américaine et française ${ }^{76}$. Plusieurs pistes récentes de l'historiographie française donnent des clés pour tenter cette approche holistique. En étudiant un autre "tranquille XVIII siècle ", celui de la France, Jean Nicolas a conclu au contraire à son «intranquillité ${ }^{77}$ » tandis que Pierre Serna a proposé l'idée audacieuse que toute révolution est une guerre d'indépendance ${ }^{78}$. Appliquées à l'Irlande, ces approches signifieraient que l'Irlande d'ancien régime et l'Irlande coloniale décrivent une même réalité. L'Irlande, mise dans la perspective atlantique, apparait alors comme un laboratoire où l'impérialisme colonial britannique et son opposition se sont inventés en miroir. Mieux comprendre le républicanisme irlandais impose donc de faire une archéologie de ces contestations, tant celles menées dans les traditions protestantes que celles des catholiques.

La tradition républicaine des Dissenters irlandais, particulièrement de l'Ulster mais également de Dublin depuis la conquête de Cromwell, et sa contribution à l'idéologie des Irlandais Unis, en y infusant un héritage républicain contestataire, sont à présent bien connues $^{79}$. Dans leur importante contribution, Anthony Di Lorenzo et John Donoghue enrichissent notre compréhension sur la manière dont la branche avancée des dissidents protestants, les antinomiens, ont articulé, dans une veine millénariste, la critique radicale du pouvoir monarchique, du colonialisme et de l'esclavage, ce dernier mot renvoyant à la fois à l'esclavage politique et à l'esclavage économique, donnant naissance à une tradition républicaine radicale qui, de la Révolution anglaise du milieu du XVII ${ }^{e}$ siècle jusqu'aux révolutions de la fin du XVIII ${ }^{e}$ siècle, s'est développée à travers l'espace atlantique. Ce républicanisme antiesclavagiste a nourri tout au long de la période une action révolutionnaire : il contribua au mouvement des Levellers pendant la Révolution anglaise en faisant de la liberté de conscience mais aussi du refus de la conscription (surtout dans la perspective de la conquête cromwellienne de l'Irlande) les principes centraux de leur lutte contre l'esclavage. Brutalement réprimés, ces antinomiens échouèrent à faire advenir la république millénariste de leurs rêves, mais leurs idées perdurèrent grâce à plusieurs passeurs de part et d'autre de l'Atlantique, et ils inspirèrent de nombreux antiesclavagistes tant aux Etats-Unis qu'en France dans leur critique des coutumes qui servaient de justification à l'esclavage. Ainsi, contrairement à ce que Bernard Baylin écrivait, la Révolution américaine ne fut pas une explosion à l'origine d'une "contagion de liberté », mais au contraire, de nombreux révolutionnaires - dont Benjamin Rush ou 
Thomas Paine - remettaient en cause l'autorité impériale britannique en puisant dans le discours radical de l'antiesclavagisme, voyant dans la promotion de l'esclavage la preuve que des institutions vénérables étaient fondamentalement corrompues et tyranniques. Le décret abolissant l'esclavage pris par la Convention en 1794 lia irrémédiablement antiesclavagisme et République ${ }^{80}$. Les républicains irlandais participèrent pleinement de ce mouvement - dont Thomas McCabe, William Drennan, Henry JoyMcCracken - en accueillant Olaudah Equiano lors de sa tournée en Irlande en 1791, en organisant des campagnes de boycott contre le sucre ou par des articles antiesclavagistes dans le Northern Star ${ }^{81}$. Thomas Russell, dans sa Letter to the People of Ireland (1796), combina le christianisme, le combat contre l'esclavage et le républicanisme. Avec le flux de réfugiés irlandais arrivant aux Etats-Unis fuyant la répression féroce menée surtout à partir de 1795, de nombreux exilés fondèrent des clubs et sociétés dans lesquels ils liaient la lutte pour la république démocratique, aux Etats-Unis et en Irlande, à la lutte pour l'abolition de l'esclavage, provoquant une hostilité haineuse chez les fédéralistes pro-esclavagistes envers les immigrés français et irlandais, justifiant les Alien et Sedition Acts de 1798 signés par John Adams et qui forcèrent le mouvement républicain antiesclavagiste avancé à devenir souterrain ${ }^{82}$.

L'historiographie consacrée aux catholiques est moins fournie, même si un débat passionné a eu lieu en Irlande pour qualifier le mécontentement exprimé lors des révoltes rurales des Houghers du Connaught en 1711-1712 qui mutilaient le bétail ${ }^{83}$, des Whiteboys $\mathrm{du}$ Munster et du sud Leinster dans la décennie 1760 qui protestaient contre les enclosures, des Rightboys opposés au paiement des dîmes destinés à l'Eglise protestante d'Irlande, et des Oakboys refusant le paiement des taxes locales, ainsi que celui exprimé lors des émeutes urbaines de la faim tout au long du siècle. Thomas Bartlett a proposé d'y voir des explosions sporadiques de colère, inscrites dans le cadre classique de l'« économie rurale » où le niveau de violence a été relativement contenu ${ }^{84}$. Pour Sean Connolly, ces mouvements, étant une défense de l'existant, étaient dénués d'un contenu politique, ce qui lui permet d'affirmer que les catholiques irlandais acceptaient dans leur ensemble la domination anglo-irlandaise protestante, réfutant ainsi l'idée d'une colonisation de l'Irlande ${ }^{85}$. Cette position est partagée par Marianne Elliott qui écrit des catholiques irlandais du XVIII ${ }^{\mathrm{e}}$ siècle qu'ils étaient " quasi-serviles dans leur loyauté ", et dont la poésie leur servait de refuge dans un monde idéalisé, tourné vers un passé mythifié ${ }^{86}$. Pourtant, chez Charles O'Conor, co-fondateur du Comité catholique militant pour l'abolition des lois pénales, dans ses Dissertations on the History of Ireland, cette exaltation du passé mythifié irlandais des septs se fait à travers le langage des Lumières, notamment françaises (il cite Montesquieu et Voltaire), pour mieux louer "l'antique Constitution » irlandaise au temps des Gaëls, par laquelle ils élisaient leur roi et tous leurs magistrats pour mieux préserver leur liberté, ce qui remet en cause «l'ordre constitutionnel » anglo-irlandais ${ }^{87}$. Pour Jim Smyth, le mécontentement populaire catholique était endémique et fut de plus en plus politisé, notamment à partir des Whiteboys ${ }^{88}$. Vincent Morley et Brendan Ó Buachalla ont montré que, des jacobites aux Whiteboys et aux Defenders républicains, une "continuité du mécontentement " peut être discernée, notamment parmi les "classes moyennes » catholiques des tenanciers, boutiquiers, artisans, aubergistes, prêtres et maîtres d'école, ces deux dernières catégories fournissant de nombreux poètes et leur position médiane dans l'échelle sociale leur permettant de refléter l'opinion des « masses rurales » avec lesquelles ils étaient en contact $^{89}$. D'ailleurs, les Defenders comptaient parmi leurs rangs des exemples de tels poètes et furent avant tout un mouvement de bourgs urbains et de villes du comté 
d'Armagh, ce qui leur a valu d'être qualifiés de "sans-culottes irlandais ", avant de se répandre dans les campagnes irlandaises ${ }^{90}$. Les Defenders eux-mêmes voyaient dans les sans-culottes français leurs pairs ${ }^{11}$. Le passage d'un mécontentement réactif à un nationalisme pro-actif se ferait, selon Vincent Morley par une adaptation constante aux circonstances politiques. Le nationalisme catholique a donc pu être jacobite, républicain, bonapartiste, o'connellite (et donc antirépublicain), parnellite et à nouveau républicain ${ }^{92}$. Jusqu'au début du XIXe siècle (et même au-delà), la population irlandaise aurait donc vu dans la France davantage que dans les Stuart ou même la république son espoir de délivrance du « joug anglais $»^{93}$.

31 Cette idée soulève de nouvelles questions sur la nature du républicanisme irlandais des années 1790. N'était-il qu'un habillage sur un mécontentement bien plus profond? Pour le dire autrement: les vrais républicains étaient-ils les Irlandais Unis, issus d'une tradition des Lumières, et les Defenders n'auraient-ils finalement pas été capables de saisir la portée des références républicaines dans leurs serments, ainsi que l'affirme Marianne Elliot ${ }^{94}$ ? Leur «républicanisme démocratique plutôt vulgaire ${ }^{95}$ » et leur " nationalisme catholique instinctif $f^{96}$ " se combinèrent-ils pour ainsi contaminer par leur « fanatisme » le républicanisme éclairé des Irlandais Unis, débouchant dans l'explosion de violence de 1798 ?

Répondre à ces questions suppose de mieux étudier la politisation à l'œuvre au cours de la décennie 1790 - et même avant - afin de mieux comprendre la nature de la transformation qui a eu lieu chez les catholiques. Thomas O'Connor a montré, à travers son étude de l'univers intellectuel et théologique de Luke Joseph Hooke, que le catholicisme irlandais, connecté avec le continent, participe pleinement au « catholicisme des Lumières" ainsi qu'aux querelles théologiques, notamment celle autour du jansénisme ${ }^{97}$. Ce catholicisme parvenait jusqu'en Irlande : Dáire Keogh a étudié l'influence de la Révolution française sur le clergé irlandais et mis en évidence une division de classe entre le haut clergé majoritairement loyaliste et le bas clergé plus hétérogène dans ses allégeances politiques ${ }^{98}$. Le rôle des prêtres dans la Révolte de 1798 a été étudié, notamment pour le soulèvement à Wexford ${ }^{99}$. Dans les deux cas, les prêtres, souvent issus de familles de marchands, formés dans les collèges irlandais en France, jouent un rôle crucial de " passeurs de révolution ${ }^{100}$. » James Coigly en est un exemple éloquent puisqu'il fait le lien entre les Defenders et la Révolution française, visible dans le caractère hybride des catéchismes et serments des Defenders, mélange de millénarisme catholique, de jacobitisme, de langage des droits naturels rappelant Paine et de références à la France révolutionnaire ${ }^{101}$. Pour ce qui concerne la population catholique plus généralement, Jim Smyth a soutenu que l'année 1792-1793 a été trop négligée par les historiens alors qu'elle voit à la fois une campagne de mobilisation populaire organisée par le Comité catholique pour élire des représentants qui se réunissent en décembre à Dublin dans une "Convention catholique», ainsi qu'une montée des violences des Defenders lorsque le gouvernement tente de créer une milice catholique pour défendre l'Irlande d'une menace d'invasion française, ce qui provoqua des émeutes dans presque toute l'Irlande et contribua à la diffusion du défendérisme ${ }^{102}$. Thomas Bartlett y voit la rupture fondamentale, celle qui met fin à l'économie morale qui prévalait jusqu'alors pour ouvrir un cycle de violence : après 1793, l'Ascendancy et le gouvernement anglo-irlandais eurent recours de manière croissante à la violence pour maintenir leur domination ${ }^{103}$.

Dans cette optique, la contribution de Tim Murtagh, étudiant les compagnons dublinois, apporte un éclairage précieux sur leur politisation. En examinant la place des artisans et 
compagnons de Dublin, rassemblés notamment dans le quartier des Liberties, Tim Murtagh montre que la présence du Parlement et le recours de plus en plus fréquent par divers patriotes - notamment Charles Lucas - aux compagnons pour faire pression sur celui-ci par la rue a été un facteur de politisation précoce. Le mécontentement, économique et social, avait donc pris très tôt des formes politiques spécifiques, et les clubs qui proliférèrent dans la capitale irlandaise dans les années 1790 et dans lesquels l'alliance entre les Irlandais Unis et les Defenders fut forgée entre 1794 et 1796 étaient les héritiers de formes d'organisation plus anciennes et autonomes. L'adoption par les artisans dublinois d'un langage de revendications inspirées de Paine ou de Volney, diffusés par la presse ou sous forme de pamphlets bon marché, a été en fait davantage une reformulation, là encore, d'une contestation plus ancienne. Les journaux dublinois conservateurs ne manquèrent pas d'y voir, dans le schéma précédemment identifié, une menace en utilisant les références à la France révolutionnaire et plus particulièrement à la «Terreur» (Marat, Robespierre, les piques, etc.) pour décrire ces clubs «jacobins", références que les compagnons eux-mêmes récupérèrent à leur propre compte. En 1798, ce sont environ 10000 artisans, compagnons et ouvriers qui sont affiliés aux Irlandais Unis et qui ressemblent bien aux sans-culottes. Dès lors, cette estimation remet en cause l'idée d'une absence de politique ou de conscience sociale dans le républicanisme des Irlandais Unis. Par leur propagande dirigée vers ces classes laborieuses, les Irlandais Unis ont cherché à répondre à leurs revendications, et s'il n'existait pas de consensus en leur sein à ce sujet, beaucoup croyaient en l'idée que le changement de régime politique permettrait aux classes populaires de faire valoir leurs demandes de plus grande égalité sociale. L'échec et la répression du projet républicain en Irlande eurent pour conséquence, là encore, un oubli mémoriel de ce radicalisme ouvrier dublinois ${ }^{104}$.

S'intéressant à un groupe très différent - les conspirations présentes parmi les matelots à bord des navires de la Navy en 1798 - mais qui soulève les mêmes enjeux, Niklas Fyrkman a renversé la perspective : ayant montré les éléments qui indiquent que la Révolte de 1798 aurait dû être accompagnée d'une mutinerie dans la flotte anglaise, il a replacé cette mutinerie avortée dans le contexte de la "République maritime» (expression qui fait écho à celle de «République flottante» employée à propos des mutins de 1797). 1798, dans cette optique, n'est pas une révolte accompagnée d'une mutinerie échouée, mais est l'extension terrestre d'une série de mutineries transatlantiques dans laquelle un projet républicain est clairement perceptible. Le rôle des Irlandais dans cette conspiration a souvent été mis en avant (voire exagéré), notamment par une historiographie conservatrice désireuse de détacher «l'Anglais loyal» de «l'Irlandais turbulent». Il est vrai que leur rôle y fut prépondérant (avec l'utilisation de la langue irlandaise pour communiquer secrètement), que le bateau sur lequel la présence de Defenders est avérée fut également celui où le lien entre une lutte plus large contre "l'esclavage et le confinement» et la lutte en faveur de la «liberté de l'Irlande» fut établi, et que la conspiration fut découverte par dénonciations de la part de certains Anglais apeurés par le «langage sectaire» employé sous les ponts. Toutefois, en réponse à une historiographie qui ne voit dans les mutineries qu'un habillage politique sur des demandes traditionnelles de la part des matelots (moins de punitions, la paie, la qualité des provisions, etc.) et qui interprètent l'échec de la conspiration de 1798 comme la preuve qu'une politisation poussée d'une minorité effraie la majorité loyale ${ }^{105}$, Niklas Frykman propose une grille de lecture différente de l'évènement : il ne s'agit pas de le comprendre comme l'importation - réussie ou ratée - d'idées politiques venues de la terre, mais, en replaçant l'épisode de 1798 dans son contexte maritime, de tenter de 
cerner les contours d'un monde "sous le pont" fait de solidarités entre radicaux Irlandais, Français républicains mais aussi loyalistes anglais, de communications secrètes entre vaisseaux et des vaisseaux vers la terre (entre la France, Hambourg, Belfast et Dublin et les vaisseaux), réseaux qui étaient une continuation de ceux forgés au moment des mutineries de 1797. La composition multinationale des équipages, le caractère nomade des flottes débouchaient nécessairement sur ce caractère transnational des mouvements de mécontentement, dès lors qu'ils s'organisaient et se structuraient ${ }^{106}$. Le ciment entre tous ces mutins était leur sentiment d'être confrontés à bord des bateaux à une société coloniale, ce qui explique qu'Irlandais et Anglais aient pu identifier leur combat comme similaire et voir dans la France leur alliée. Ainsi l'utilisation d'un langage révolutionnaire (les matraques sont des "arbres de la liberté ", l'assassinat des officiers se fera par l'action de la "guillotine »), la volonté de prendre le contrôle des navires et de les conduire dans les ports français, le rôle des Irlandais Unis et des Defenders, l'utilisation très flexible d'un vocabulaire ethnique ou religieux suggèrent que la «république maritime» s'est construite dans un processus de synergie avec les circulations républicaines atlantiques ${ }^{107}$.

\section{La République : indépendance, nation, souveraineté}

L'échec de 1798 a donc été multiple, car il a permis la mise en œuvre d'une grille de lecture sectaire de la révolte, la réduisant à une vengeance religieuse fanatique. Dès lors, il est difficile de savoir ce qu'aurait été ce républicanisme s'il avait été instauré en Irlande. Beaucoup d'historiens acceptent l'idée que si une révolution avait bien eu lieu en Irlande, elle se serait traduite par un bain de sang, favorisé par les présences des troupes françaises, avant que la France ne transforme l'Irlande en un état-satellite à l'instar des républiques-sœurs, la saignant à blanc pour alimenter son impérialisme, ou ne l'abandonne à l'Angleterre en échange d'une quelconque île à sucre ${ }^{108}$. De là, dans une synthèse d'histoire contrefactuelle, Brendan Simms en conclut que, puisque les catholiques insurgés de Wexford ou du Mayo ressemblaient davantage, y compris dans leurs vêtements et leurs médaillons catholiques, aux Vendéens ou aux Sanfedisti de l'Italie du sud, une invasion française réussie en Irlande aurait été «le commencement d'un nouveau traumatisme» puisque les Français auraient davantage soutenu les presbytériens contre des catholiques identifiés à des contre-révolutionnaires ${ }^{109}$.

Le rôle des troupes françaises est ici chargé de sens ambivalent : alors que de nombreux historiens ont souligné le fait que les Irlandais Unis voyaient dans les armées françaises une manière de contenir le déchaînement de violence qu'une insurrection populaire entrainerait, d'autres considèrent que leur présence aurait précisément favorisé cette violence. Les quelques exemples issus de l'épreuve des faits montrent que si les débordements prévisibles lorsqu'une population civile est enrôlée dans un contexte colonial pour se soulever contre le pouvoir établi et incarné localement par l'élite des propriétaires ont eu lieu, les troupes françaises, et les Irlandais venus de France qui les accompagnaient, cherchèrent à éviter les massacres socio-religieux ${ }^{110}$. Qu'en est-il des intentions réelles de la France à l'égard de l'Irlande? Ici, les instructions données aux différents commandants des expéditions militaires, les proclamations rédigées par des Irlandais en collaboration avec l'état-major français et adressés aux Irlandais, et les traces des négociations entre les émissaires irlandais et le Directoire permettent de répondre à cette question de manière quelque peu solide ${ }^{111}$. Parmi elles, le journal de Tone est une 
source exceptionnelle, car il y écrit quotidiennement le résultat de ses entrevues avec les plus hauts responsables français. Sylvie Kleinman revient sur la manière avec laquelle s'est négociée la souveraineté irlandaise entre Tone et le Directoire ${ }^{112}$, ce qui lui permet de mieux examiner la relation entre la France et le projet «utopique» d'une Irlande indépendante et souveraine, relation qui se traduit également par l'utilisation de symboles incarnant le projet républicain et adaptés à l'Irlande, tels le drapeau vert et la devise "Erin Go Bragh ", qui sont très vite identifiés comme tels par les opposants au républicanisme, comme Pascal Dupuy l'a montré. Le langage tenu par la République française à l'égard de l'Irlande a bien évolué entre 1796 et 1798 : les instructions et proclamations voient dans les Irlandais Unis des «frères » et des «citoyens du Monde persécutés par un gouvernement féroce, ennemi de tous les hommes libres»; la discipline est prescrite aux troupes françaises pour servir de modèle aux Irlandais; les mœurs les usages et les pratiques religieuses des Irlandais doivent être respectés « et dans aucun cas qu'il [ne] soit porté atteinte aux personnes et aux propriétés ${ }^{113}$.»

Dernier aspect: la stratégie globale de la France. S'il faut tenter d'imaginer ce qu'aurait signifié une victoire en Irlande, il faut le faire jusqu'au bout dans le contexte du moment. Privée de l'Irlande, l'Angleterre aurait-elle pu mobiliser autant de ressources dans la guerre qu'elle menait contre la France républicaine? La coalition continentale aurait-elle pu continuer sans elle et la paix n'aurait-elle pas alors découlé nécessairement? Sans la situation de guerre, la menace contre-révolutionnaire se serait effondrée, et la France aurait-elle subi autant de tentatives de coups d'Etat et donc autant de crispations de régime? Aurait-elle eu recours à ses généraux-conquérants? Un Bonaparte aurait-il pu alors se poser en sauveur? Soulever ces questions, c'est s'empêcher d'y répondre. En réalité, derrière elles, se niche la question, plus immédiatement pertinente, de l'exceptionnalisme britannique (ou anglais). Face à une France révolutionnaire où la république est remplacée par un régime dictatorial, impérialiste et à nouveau esclavagiste, la Grande-Bretagne propose à l'Irlande post-Union un autre modèle d'intégration, un modèle impérial, monarchique et libéral dans lequel elle peut espérer bénéficier d'une "trickle-down liberté ». Ce modèle de l'exceptionnalisme britannique hante encore l'historiographie et la conscience irlandaises d'autant que les espérances ont été en grande partie comblées (émancipation catholique, transfert massif de propriété) au cours du XIX ${ }^{e}$ siècle ${ }^{114}$, sauf en ce qui concerne le self-government avec le Home Rule, promis, mais jamais appliqué ${ }^{115}$. A un exceptionnalisme britannique peut-être faudrait-il chercher à comparer l'Irlande avec ses sœurs en républiques, les Etats-Unis et la France, ou les plus récentes républiques est-européennes, pour mieux souligner, comme l'a récemment fait Tommy Graham, son exceptionnelle (pour le coup) réussite : seule nation ayant gagné son indépendance contre un empire victorieux de la Première Guerre mondiale, seul pays nouvellement souverain à ne pas être tombé dans une régime autoritaire même après une guerre civile, l'Irlande républicaine a servi de modèle à bien d'autres colonies désireuses d'indépendance ${ }^{116}$.

C'est bien ici l'enjeu : le mot république a incarné, à la fin du XVIII e siècle, en Irlande, un espoir d'autonomie, au sens rousseauiste et kantien du terme soit, à l'échelle d'une nation, de souveraineté. Cet espoir est républicain en ce sens où, précisément, il consiste pour tous ceux qui y ont œuvré à établir l'empire des lois au lieu de l'empire (colonial britannique) des hommes ${ }^{117}$. La violence - religieuse, sociale, politique - déployée alors est indéniable, mais elle a effacé ce que recouvraient le projet républicain et ses différentes composantes, non sans contradiction entre elles. Le républicanisme irlandais 
pouvait aussi bien incarner les aspirations de protestants issus de la classe dominante en rupture avec leur milieu, de presbytériens, de catholiques et de protestants des classes moyennes revendiquant une participation aux affaires de la Cité, de paysans, ouvriers, matelots (catholiques ou non) espérant mettre fin à l'oppression, plus d'égalité et de justice. Il n'était pas seulement un projet d'inclusion confessionnelle et séculaire comme les Irlandais Unis l'avaient formulé, mais il est aussi une réponse à une fragmentation sociale de classe.

Encore faut-il interroger précisément ce qui se joue dans l'adéquation entre républicanisme et indépendantisme. Etre indépendants signifiait, pour les Irlandais, pouvoir faire eux-mêmes leurs propres lois, et donc exister en tant que nation souveraine. De là, il apparaît que, $a$ contrario du célèbre credo de Tone ${ }^{118}$, le nationalisme ne précède pas l'indépendantisme, mais c'est le contraire. Pour pouvoir créer une nation, au sens révolutionnaire, moderne, du terme, c'est-à-dire une communauté politique, les Irlandais, pour être unis, avaient besoin d'être indépendants. Tant qu'ils ne l'étaient pas, et puisqu'ils ont échoué à le devenir, le gouvernement n'était pas légitime, même s'il était légal. C'est pourquoi, par la suite, le républicanisme a prétendu incarner cette légitimité, même et surtout si les républicains étaient minoritaires.

Ainsi, eu égard aux différentes composantes sociales qui en étaient le moteur, le républicanisme irlandais était fondamentalement révolutionnaire et démocratique. En l'adoptant comme le langage de la contestation, non plus simplement au nom de la défense d'un ordre menacé ou disparu, les mécontents ont ainsi contribué à détruire pour de bon cet ancien ordre, propulsant leur pays dans un horizon d'attente qui, s'il n'est pas advenu - et par essence ne peut jamais advenir totalement - a été constitutif de la modernité en Irlande. En cela, les insurgés irlandais se démarquent fondamentalement des révoltés vendéens ou napolitains : ils ne sont pas simplement dans la réaction qui les fait passer de l'anti-révolution à la contre-révolution, mais, au contraire, sont aussi proactifs $^{119}$. Ainsi, étudier le républicanisme irlandais dans la République atlantique permet à la fois de l'extraire de son signifié nationaliste plus récent (et plus conservateur) pour mieux comprendre qu'à la fin du XVIII siècle, le nationalisme signifiait l'indépendance et donc la souveraineté politique de la nation soit la promesse de la république démocratique. Le nœud originel entre républicanisme, nationalisme, indépendance et violence ne peut être que mieux compris dans cette perspective.

\section{NOTES}

1. Sur Tone et les Irlandais Unis: David DICKSON, Dáire KEOGH, Kevin WHELAN (dir.), The United Irishmen. Republicanism, Radicalism and Rebellion, Dublin, The Lilliput Press, 1993 et La Révolution française [En ligne], 11 | 2016. URL : http://lrf.revues.org/citer ce numéro.

2. Henri Jacques Guillaume Clarke (1765-1818), futur duc de Feltre, était à la tête du Cabinet historique et topographique militaire, soit la branche militaire du secrétariat du Directoire. Il était un ancien protégé du duc d'Orléans et le bras droit de Carnot. 
3. Pour une présentation d'ensemble, voir deux approches devenues classiques: Thomas BARTLETT, Ireland. A History, Cambridge, Cambridge University Press, 2010, chap. 4 («Ireland's Long Eighteenth Century, 1691-1830»), p.141-266; Roy F. FOSTER, Modern Ireland, 1600-1972, London, Penguin Books, 1989 (1988), p. 167-317.

4. Theodore W. MOODY, Robert B. MCDOWELL, Christopher J. WOODS (dir.), The Writings of Theobald Wolfe Tone, 1763-1798, 3 vol., Oxford, Clarendon Press, 1998, 2001 et 2007, vol. II, p. 109-246 (ci-après : The Writings of Theobald Wolfe Tone).

5. Tone écrivait, le 14 mars 1796, suite à sa première rencontre avec Clarke: «[ses] idées politiques sur l'Irlande ont au moins trente ans de retard sur celles du peuple» (Ibid, p. 113). Le 13 avril 1796, Tone fustige Clarke et Ysabeau, le premier secrétaire du ministre des Relations extérieures Delacroix, comme étant respectivement, le premier « rempli de préjudices flagrants » et le second «totalement ignorant» (Ibid., p. 153). Toutes les traductions proposées ici sont les nôtres.

6. Entrée du 21 mars 1796, Ibid., p. 118.

7. Observations de Tone sur les instructions données à Eugène Aherne, 22 avril 1796, Ibid., p. 159.

8. Jean-Claude NOËL, "Images de l'Irlande dans la conscience française au XVIII ${ }^{e}$ siècle ", Cahiers irlandais, n6, 1981, p. 7-56; Graham GARGETT, Geraldine SHERIDAN (dir.), Ireland and the French Enlightenment, 1700-1800, Basingstoke and New York, MacMillan / St. Martin's Press, 1999, p. 127-170 ; Gilles LE BIEZ, «Irish News in the French Press: 1789-98 », dans David DICKSON, et alli ( dir.), The United Irishmen. Republicanism, Radicalism and Rebellion, op. cit. p. 256-268.

9. Hoche au Directoire, 28 messidor an IV (16 juillet 1796), AN AF III 186B, doss. 859, p. 58.

10. Sur la volonté de la France de prendre l'Angleterre à revers et d'utiliser l'Irlande comme une Vendée pour l'Angleterre: Sylvie Kleinman, «Initiating insurgencies abroad: French plans to 'chouannise' Britain and Ireland, 1793-1798», Small Wars \& Insurgencies, vol. 25, nº, 2014, p. 784-799. Hoche semble avoir été « converti » à l'idée d'un républicanisme irlandais à mesure que les préparatifs de l'expédition avançaient et, jusqu'à la veille de sa mort en septembre 1797, il promettait à Tone de retenter l'aventure malgré l'échec de Bantry.

11. Sur 1798, l'ouvrage désormais incontournable est: Thomas BARTLETT, David DICKSON, Dáire KEOGH, Kevin WHELAN (dir.), 1798, A Bicentenary Perspective, Dublin, Four Courts Press, 2003. En français, on ne peut que constater un trou historiographique béant. Une présentation succincte récente a été proposée par Pascal DUPUY, « La Grande Rébellion irlandaise de 1798 : répression et tentative d'union », Cahiers d'histoire. Revue d'histoire critique [En ligne], 94-95, 2005, mis en ligne le 01 janvier 2008. URL : http://chrhc.revues.org/1085.

12. Dáire KEOGH, Kevin WHELAN (dir.), Acts of Union. The Causes, Contexts, and Consequences of the Act of Union, Dublin, Four Courts Press, 2001.

13. Patrick GEOGHEGAN, Robert Emmet: A Life, Dublin, McGill \& Macmillan, 2002 ; Ruán o'DonnelL, Robert Emmet and the Rebellion of 1798 et Robert Emmet and the Rising of 1803, Dublin, Irish Academic Press, 2003, propose une biographie avec un appareil de notes particulièrement fourni.

14. Hugh GOUGH, Gilles LE BIEZ, «Un républicanisme ambigu : l'Irlande et la Révolution française », AHRF, n²96, avril-juin 1994, p. 321-330.

15. Sur cette décennie fondatrice de l'histoire irlandaise, l'un des travaux les plus solides dont le titre programmatique relie les deux termes est: Charles TOWNSHEND, The Republic. The Fight for Irish Independence, 1918-1923, London, Allen Lane, 2013. Sur la longue histoire de la République en Irlande : Karin FISCHER, Clíona NÍ RÍORDÁIN (dir.), L'Irlande et sa république : passée, présente et à venir/ Ireland's Republic : Past, Present and Future, Etudes irlandaises, vol. 41, n², automne-hiver 2016.

16. Richard V. COMERFoRD, «Republicans and Democracy in Modern Irish Politics ", dans Fearghal McGarry (dir.), Republicanism in Modern Ireland, Dublin, University College Dublin Press, 2003, p. 8-22. Sur l'idée que le républicanisme armé élitiste remonte aux années 1790 : Sean J. connolly, «The Limits of Democracy: Ireland, 1775-1848», dans Joanna Innes, Mark Philp (dir), Re- 
Imagining Democracy in the Age of Revolutions: America, France, Britain, Ireland, 1750-1850, Oxford, Oxford University Press, 2013, p. 174-190. Sur l'idée de hiatus entre le légitime et le légal : Pierre SERNA, «Est-ce ainsi que naît une république? ", dans Claudia Moatti, Michèle Riot-Sacrey (dir.), La république dans tous ses états. Pour une histoire intellectuelle de la république en Europe, Paris, Payot, 2009, p. 23-56.

17. Voir l'avant-propos de Thomas BARTLETT, «Writing the history of the revolutionary 1790s during the "Troubles": historiographical and moral dilemmas », La Révolution française [En ligne], 11 | 2016. URL : http://lrf.revues.org/citer ce numéro ; John REAGAN, « Dr Jekyll and Mr Hyde: 'the Two Histories'», History Ireland, n¹, January/February 2012. URL: http:// www.historyireland.com/20th-century-contemporary-history/dr-jekyll-and-mr-hyde-the-twohistories-2/

18. Cette chaîne de liens a été établi par Padraig Og O’Ruairc dans une conférence donnée le 17 février 2016 au People's College for continuing education \& training à Dublin intitulée «The Proclamations of 1803, 1867 \& 1916 ». Un symposium, « The 1916 Proclamation in its National and International Contexts ", a également eu lieu à Trinity College Dublin, en avril 2016. A écouter : https://soundcloud.com/tlrhub/sets/the-1916-proclamation-in-its.

19. Cette journée d'étude eut lieu en Sorbonne, ce qui fut une première. Sa tenue et sa réussite furent permises grâce au soutien indéfectible du Professeur Pierre Serna, et du Professeur Bruno Belhoste, directeur de l'IHMC, au travail de Marie-Michèle Talis, au professionnalisme et à la réactivité de Serena Trovarelli (IHMC), à l'aide de Toby Frajerman, de Marilyne Delbès et de Cécile Peter pour avoir régulièrement mis à jour les sites Internet de l'IHRF et de l'IHMC et, bien sûr, grâce à la participation de tous les intervenants. Thomas Bartlett, Yevan Terrien, Hugh Gough et Pierre Serna ont respectivement accepté d'ouvrir, de mener une discussion et de conclure cette journée. Sylvie Kleinman contribua également à la traduction du programme et fut une liaison avec Dublin. Qu'ils en soient tou-te-s ici remercié-e-s.

20. Outre la réédition du classique de Robert R. PALMER, The Age of Democratic Revolution. A Political History of Europe and America, 1760-1800, Princeton and Oxford, Princeton University Press, 2014, on notera parmi une large production: Manuela ALBERTONE, Antonino DE FRANCESCO, Rethinking the Atlantic World: Europe and America in the Age of Democratic Revolutions, Ithaca, Palgrave Macmillan, 2009 ; David armitage, Sanjay subrahmanyam (dir.), The Age of Revolutions in Global Context, $c$. 1760-1840, New Nork, Palgrave Macmilan, 2010 ; Suzanne DESAN, Lynn HUNT, William Max NELSON (dir.), The French Revolution in Global Perspective, Ithaca, Cornell University Press, 2013 ; Joanna INNES, Mark PHILP (dir.), Re-Imagining Democracy, op. cit. ; Janet POLASKY, Revolutions Without Borders: The Call to Liberty in the Atlantic World, Yale, Yale Universsity Press, 2015 ; Michael A. MCDONNELL (dir.), Rethinking the Age of Revolution, Atlantic Studies/Global Currents, vol. 13, n³, 2016.

21. Voir, parmi une littérature à présent florissante : John G. A. Рососк, The Machiavellian Moment: Florentine Political Thought and the Atlantic Republican Tradition, Princeton, Princeton University Press, 1975 ; Philip PETTIT, Republicanism. A Theory of Freedom and Government, Oxford, Oxford University Press, 1997; Quentin SKINNER, Liberty Before Liberalism, Cambridge, Cambridge University Press, 1998.

22. Pierre SERNA, «Le Directoire, miroir de quelle République?», dans Pierre Serna (dir.), Républiques sœurs. Le Directoire et la Révolution atlantique, Rennes, PUR, 2009, p. 7-20.

23. Sur l'idée de la force d'une république possible mais non advenue, ou plutôt, en l'occurrence, advenue puis disparue en France, et de la force qu'elle peut représenter à la fois comme horizon d'attente toujours renouvelé et comme réservoir de références et de pratiques: Michèle RIOTSARCEY, Le procès de la liberté. Une histoire souterraine du XIX ${ }^{e}$ siècle, Paris, La Découverte, 2016.

24. Thomas BARTLETT, «Why the History of the 1798 Rebellion Has Yet to Be Written », EighteenthCentury Ireland / Iris an dá chultúr, Vol. 15, 2000, p. 181-190. 
25. Trois articles sont ici fondamentaux : Sean J. CONNOLLY, « Eighteenth-Century Ireland, Colony or Ancien Régime?», dans David George Boyce, Alan O’Day (dir.), The Making of Modern Irish History. Revisionism and the Revisionist Controversy, London \& New York, Routledge, 1997 (1996), p. 15-33; Jim SмYтH, «Introduction: the 1798 Rebellion in its Eighteenth-Century Contexts ", dans Id. (éd.), Revolution, Counter-revolution and Union: Ireland in the 1790s, Cambridge, Cambridge University Press, 2000, p.1-20; Harry T. DICKINSON, "L'Irlande à l'époque de la Révolution française", AHRF [en ligne], n³42, octobre-novembre 2005, URL: http:// ahrf.revues.org/1929.

26. Voir Kevin WHELAN, "' 98 after ' 98 », dans Kevin Whelan, The Tree of Liberty. Radicalism, Catholicism and the Construction of Irish Identity, 1760-1830, Cork, Cork University Press \& Field Day, 1996, p. 133-175; Nicholas FURLong, "The Church and Fr John Murphy of Boolavogue, 1753-1798 », dans Liam Swords (dir.), Protestant, Catholic \& Dissenter: the Clergy and 1798, Dublin, The Columba Press, 1997, p. 186-218.

27. Laurent COLANTONIO, «Les nationalistes irlandais et les républicains français au début du XIX ${ }^{\mathrm{e}}$ siècle: l'impossible rencontre", La Révolution française [En ligne], 11|2016. URL: http:// lrf.revues.org/citer ce numéro ; Laurent COLANTONIO, "Mobilisation nationale, souveraineté populaire et normalisations en Irlande (années 1820-1840) ", Revue d'histoire du XIX ${ }^{e}$ siècle [En ligne], n42, 2011, URL: http://rh19.revues.org/4105 ; Laurent CoLANTONIO, " "Democracy" and the Irish People, 1830-1848», dans Joanna Innes, Mark Philp (dir), Re-imagining Democracy, op. cit., p. 162-173.

28. Richard R. MADDEN, The United Irishmen: Their Lives and Times, $1^{\text {st }}$ ser., 7 vol., London and Dublin, 1842-1846, $2^{\text {nd }}$ ser., 4 vol., Dublin and London, 1857-1860 ; Christopher J. wooDS, «R. R. Madden, historian of the United Irishmen », démontre, dans Thomas Bartlett, David Dickson, Dáire Keogh, Kevin Whelan (dir.), 1798, A Bicentenary Perspective, op. cit., p. 497-511, que Madden était à la fois progressiste et fréquentait les milieux catholiques conservateurs, ce qui a influencé son appréciation des Irlandais Unis.

29. James A. FROUDE, The English in Ireland in the Eighteenth Century, London, 1872-1874.

30. William E. H. LECKY, History of Ireland in the Eighteenth Century, 5 vol., London, 1898.

31. Sur les lois pénales, voir Thomas BARTLETT, D. W. HAYTON, Penal Era and Golden Age: Essays in Irish History, 1690-1800, Belfast, Ulster Historical Foundation, 2005 (1979).

32. Daniel CORKERY, The Hidden Ireland: A Study of Gaelic Munster in the Eighteenth Century, Dublin, M. H. Gill \& Son, 1924

33. Sur le révisionnisme irlandais concernant la période de la fin du XVIII ${ }^{\mathrm{e}}$ siècle, voir également : Nancy CURTIN, « 'Varieties of Irishness': Historical Revisionism, Irish Style », Journal of British Studies, vol. 35, $\mathrm{n}^{\circ}$ 2, April 1996, p. 195-219.

34. Maureen WALL, "The Rise of a Catholic Middle Class in the Eighteenth-Century Ireland », Irish Historical Studies, vol. XI, n42, September 1948, p. 91-115; Louis M. CULLEN, « The 1798 Rebellion in its Eighteenth-Century Context», dans P. J. Corish (dir.), Radicals, Rebels and Establishments, Historical Studies xv, Belfast, Apple Tree Press, 1985.

35. James C. BECKETT, The Anglo-Irish Tradition, London, Faber and Faber, 1976, p. 63.

36. A. cosGrove, Francis X. MARTIN, Theodore W. MOODY, W. E. VAUGHAN, (dir.), A New History of Ireland , tome IV, Eighteenth-century Ireland, Oxford, Oxford University Press, 1986 ; Thomas BARTLETT, « A New History of Ireland ", Past \& Present, n¹16, August 1987, p. 206-219.

37. Marianne ELLIOTT, Partners in Revolution: The United Irishmen and France, New Haven, éditeur? 1982.

38. Nancy J. CURTIN, The United Irishmen: Popular Politics in Ulster and Dublin, 1791-1798, Oxford, 1994 ; Nancy J. CURTIN, «The transformation of the Society of the United Irishmen into a massbased revolutionary organization, 1794-1796», Irish Historical Studies, vol. XXIV, n96, novembre 1985, p. 463-492. 
39. Voir également Marianne ELLIOTT, "The Origins and Transformation of the Early Irish Republicanism ", International Review of Social History, vol. XXIII, 1978, p. 406-428 ; Marianne ELLIOTT, Wolfe Tone: Prophet of Irish Independence, New Haven and London, Yale University Press, 2012 (1989).

40. Voir Ian MCBRIDE, Eighteenth-Century Ireland, The Isle of Slaves, New Gill History of Ireland, vol. 5, Dublin, Gill \& Macmillan, 2009, p. 12-14 pour l'historiographie de cette notion importée depuis l'Angleterre dans son acceptation tory.

41. Sean J. connolly, «Eighteenth-Century Ireland. Colony or Ancien Régime? », art. cit., p. 27 ; C.

D. A. Leighton, Catholicism in a Protestant Kingdom. A Study of Irish Ancien Régime, Basingstoke, Macmillan, 1994.

42. Nicholas CANNY, "Irish Resistance to Empire? 1641, 1690 and 1798 », dans Lawrence Stone (dir.), An Imperial State at War: Britain from 1689 to 1815, London, Routledge, 1994, p. 316.

43. Mary HAyden, George moonan, A Short History of the Irish People, 1921, cité dans Jim Smyth, «Introduction », art. cit., p. 2.

44. James C. BECKETT, The Anglo-Irish Tradition, op. cit., p. 82-83.

45. Sean J. CONNOlly, "Review of Rebellion and Remembrance in Modern Ireland, and Revolution, Counter-Revolution and Union: Ireland in the 1790s ", History Ireland, Volume 9, Issue 2, Summer 2001, p. 46.

46. Sean J. CONNOLly, «Eighteenth century Ireland. Colony or Ancien Régime? », dans David George Boyce, Alan O’Day (dir.), The Making of Modern Irish History, op. cit., p. 28.

47. Kevin WHELAN, "Introduction to Section I ", dans Thomas Bartlett, David Dickson, Dáire Keogh, Kevin Whelan (dir.), 1798, A Bicentenary Perspective, op. cit., p. 9, note 45.

48. François CROUZET, "The Second Hundred Years War. Some Reflections », French History, vol. $10, \mathrm{n}^{\circ} 4,1996$, p. 432-450; Renaud MORIEUX, Une mer pour deux royaumes. La Manche, frontière francoanglaise (XVII ${ }^{e}$-XVIII ${ }^{e}$ siècles), Rennes, PUR, 2008, p. 17-21.

49. David A. BELL, The First Total War, Napoleon's Europe and the Birth of Warfare as We Know it, Boston \& New York, Houghton Mifflin Company, 2007.

50. Les débats autour du livre de David Bell ont été nombreux, voir ceux entre lui et Pierre Serna, sur le site de l'IHRF : http://ihrf.univ-paris1.fr/centre-de-documentation/controverses/autourde-the-first-total-war-de-d-bell/; voir également David BELL, Annie CRÉPIN, Hervé DREVILLON, Olivier FORCADE et Bernard GAINOT, « Autour de la guerre totale ", AHRF [En ligne], n³66, octobredécembre 2011. URL : http://ahrf.revues.org/1223. Et les débats en anglais dans le volume II (2007) du H-France Forum : http://h-france.net/forum/h-franceforumvol2.html.

51. Pierre SERnA, Antonino DE fRANCESCO, Judith A. MILlER (dir.), Republics at War, 1776-1840. Revolutions, Conflicts and Geopolitics in Europe and the Atlantic World, Basingstoke \& New York, Palgrave Macmillan, 2013.

52. Pierre SERNA, "Introduction: War and Republic: Dangerous Liaisons », dans Pierre Serna, Antonino de Francesco, Judith A. Miller (dir.), Republics at War, op. cit., p. 1-23.

53. Voir aussi : Thomas BARTLETT, "Ireland in an Era of Total War, 1790-1815 ", dans Thomas Bartlett (dir.), History of Ireland, à paraître. Je remercie Thomas Bartlett de m'avoir permis de lire cet article.

54. Stephen SMALL, Political Thought in Ireland, 1776-1798. Republicanism, Patriotism and Radicalism, Oxford, Clarendon Press, 2002 ; Thomas BARTLETT, Ireland. A History, op. cit., p. 174-206.

55. Tone à Thomas Russell, 9 juillet 1791, The Writings of Theobald Wolfe Tone, vol. I, op. cit., p. 104-106.

56. Lettre ouverte de la Société des Irlandais Unis de Dublin, 30 décembre 1791, Ibid., p. 155.

57. Tone à Thomas Russell, 9 juillet 1791, Ibid., p. 104-106.

58. «Quelle réponse pourrions-nous apporter aux catholiques d'Irlande s'ils venaient à [...] demander leurs droits en tant que Citoyens et en tant qu'Hommes? Quelle réponse, recevable à 
Dieu et à notre conscience ? Aucune. Nous jacassons et bredouillons, et écrivons des livres, et les publions, remplis des sentiments de la liberté et de l'abhorrence de la tyrannie et des plus hautes louanges pour les Droits de l'Homme! Cependant nous nous satisfaisons de maintenir trois millions de créatures qui sont nos semblables et sujets comme nous dans un état de dégradation et d'infamie et de mépris, ou, pour le résumer un mot, en esclavage!» (Ibid., p. 125).

59. Stephen SMALL, Political Thought in Ireland, op. cit., p. 19-25 ; Liam CHAMBERS, «A Displaced Intelligentsia: Aspects of Irish Catholic Thought in Ancien Régime France ", dans Thomas O'Connor (dir.), The Irish in Europe, 1580-1815, Dublin, Four Courts Press, 2001, p. 158-174.

60. Pour Raymonde MONNIER, "Que signifie "être républicain" en septembre 1792 ? ", dans Michel Biard, Philippe Bourdin, Hervé Leuwers, Pierre Serna (dir.), 1792. Entrer en république, Paris, Armand Colin, 2013, p. 37-49, « les principes de la Déclaration des droits dessinent l'horizon de la République " (p. 39).

61. Références complètes

62. Pour Burke, l'union était la meilleure réponse au problème irlandais : ainsi débarrassée d'un parlement caractérisé par l'esprit de province et la bigoterie d'une classe dominante protestante, l'Irlande serait intégrée au centre impérial en envoyant des députés à Westminster, assurant ainsi une véritable représentation de l'île : Robert B. MCDOWELL, «Burke and Ireland », dans David Dickson et alli (dir.), The United Irishmen, op. cit., p. 102-114.

63. John DARWIN, The Empire Project. The Rise and Fall of the British World-System, 1830-1970, Cambridge, Cambridge University Press, 2009. Darwin date l'émergence de ce système-monde dans les années 1820-1830, suite à la victoire britannique dans les guerres napoléoniennes.

64. Edmund BURKE, Reflections on the Revolution of France, London, Printed for J. Dodsley, 1791 (1790, $10^{\mathrm{e}}$ éd.), p. 73-78.

65. Kevin WHELAN, The Tree of Liberty, op. cit., p. 37.

66. Thomas BARTLETT, The Fall and Rise of the Irish Nation. The Catholic Question, 1690-1830, Dublin, Gill \& Macmillan, 1992, chap. 8 et 9.

67. Dáire KEOGH, The French Disease. The Catholic Church and Irish Radicalism, 1790-1800, Dublin, Four Courts Press, 1993, p. 27.

68. Pascal DUPUY, «Le républicanisme « maudit » aux Etats-Unis, en France et en Irlande d'après les images anglaises », La Révolution française [En ligne], 11 | 2016. URL : http://lrf.revues.org/citer ce numéro; également: Gerard O'BRIEN, «Francophobia in Later Eighteenth-Century Irish History ", dans Hugh Gough, David Dickson (dir.), Ireland and the French Revolution, op. cit., p. 40-51. 69. Mathieu FERRADOU, «Histoire d'un "festin patriotique" à l'hôtel White (18 novembre 1792) : les Irlandais patriotes à Paris, 1789-1795 ", AHRF, n³82, décembre 2015, p. 123-143.

70. Guillaume GLÉNARD, «La République des origines, 10 août 1792-21 janvier-6 avril 1793 », dans Michel Biard, Philippe Bourdin, Hervé Leuwers, Pierre Serna (dir.), 1792. Entrer en république, op. cit., p. 23-35 (p. 23).

71. Sur la conception «nomade» du patriotisme républicain telle que Thomas Paine l'avait exprimée à travers sa réponse à Franklin ("Where liberty is, there is my country ») : "Where liberty is not, this is my country ", voir Gilles BERTRAND et Pierre SERNA (dir.), La République en voyage, 1770-1830, Rennes, PUR, 2013.

72. Rachel ROGERS, " "Their cause then and ours is the same": The British and Irish in the Parisbased Society of the Friends of the Rights of Man, 1792-94 ", La Révolution française [En ligne], 11 | 2016. URL : http://lrf.revues.org/citer ce numéro.

73. Ultán GILLEN, "Constructing Democratic Thought in Ireland in the Age of Revolution, 1775-1800 », dans Joanna Innes, Mark Philp (dir.), Re-Imagining Democracy, op. cit., p. 149-161.

74. Dans un schéma identifié par Jean-Clément MARTIN, Contre-Révolution, Révolution et Nation en France, 1789-1799, Paris, Seuil, 1998, notamment le chapitre 1: «Au début était la ContreRévolution », p. 14-57. 
75. Ian MCBRIDE, Eighteenth-Century Ireland, The Isle of Slaves, op. cit., page?

76. Ibid., p. 156.

77. Jean NICOLAS, La Rébellion française. Mouvements populaires et conscience sociale (1661-1789), Paris, Seuil, 2008 (2002).

78. Pierre SERNA, "Toute révolution est guerre d'indépendance", dans Jean-Luc Chappey, Bernard Gainot, Guillaume Mazeau, Frédéric Régent, Pierre Serna, Pour quoi faire la Révolution, Marseille, Agone, 2012, p. 19-49.

79. Anthony T. Q. STEWART, A Deeper Silence. The Hidden Origins of the United Irishmen, London and Boston, Faber and Faber, 1993 ; Ian R. MCBRIDE, Scripture Politics. Ulster Presbyterians and Irish Radicalism in Late Eighteenth-Century Ireland, Oxford, Clarendon Press, 1998 ; Fergus WHELAN, Dissent Into Treason. Unitarians, King-killers and the Society of United Irishmen, Brandon, Dingle \& London, 2010.

80. Pierre SERNA, «Que s'est-il dit à la Convention les 15,16 et 17 pluviôse an II ? Ou lorsque la naissance de la citoyenneté universelle provoque l'invention du «crime de lèse-humanité » ", $L a$ Révolution française [En ligne], $n^{\circ} 7,2014$. URL : http://lrf.revues.org/1208.

81. Voir également Peter Linebaugh, " "A Dish with One Spoon”: American Experience and the Transformation of Three Officers of the Crown ", dans Thomas Bartlett, David Dickson, Dáire Keogh, Kevin Whelan (dir.), 1798, A Bicentenary Perspective, op. cit. p.642-657; Nini ROGERS, "Ireland and the Black Atlantic in the Eighteenth Century », Irish Historical Studies, XXXII, n ${ }^{\circ} 126$, novembre 2000, p. 174-192.

82. Anthony DI LORENZO, John DONOGHUE, « Abolition and Republicanism over the Transatlantic Longue Durée, 1640-1800 », La Révolution française [En ligne], 11 | 2016. URL : http://lrf.revues.org/ citer ce numéro.

83. Notons, avec Ian MCBRIDE, Eighteenth-Century Ireland, op. cit., p. 47-49, que cette pratique de couper les tendons du bétail a été appliqué aux soldats anglais tout au long du siècle !

84. Thomas BARTLETT, «An End to Moral Economy: the Irish Militia Disturbances of 1793 ", Past \& Present, vol. 99, n¹, mai 1983, p. 41-64.

85. Sean J. ConNolly, Religion, Law and Power: The Making of Protestant Ireland, 1660-1760, Oxford, editeur?? 1992, p. 217, cité par Ian MCBRIDE, Eighteenth-Century Ireland, op. cit., p. 49.

86. Marianne ELLIOTT, Partners in Revolution, op. cit., p. 3-7.

87. Charles O'CONOR, Dissertations on the Ancient History of Ireland..., Dublin, editeur/libraire??(si possible) 1753 , p. $76-83$.

88. Jim SMYTH, The Men of No Property: Irish Radicals and Popular Politics in the late Eighteenth Century, Palgrave Macmillan, Basingstoke \& London, 1992, notamment le chap. 2.

89. Brendan Ó BUACHALlA, "From Jacobite to Jacobin », dans Thomas Bartlett, David Dickson, Dáire Keogh, Kevin Whelan (dir.), 1798, A Bicentenary Perspective, op. cit. p. 75-96; Vincent MORLEY, Irish Opinion and the American Revolution, 1760-1783, Cambridge, Cambridge University Press, 2002 ; Vincent MORLEY, "The Continuity of Disaffection in Eighteenth-Century Ireland ", EighteenthCentury Ireland/Iris an dá chultúr, vol. 22, 2009, p. 189-205.

90. Marianne ELLIOTT, Partners in Revolution, op. cit., p. 41.

91. Voir leurs serments où ils évoquent des «Defenders français»: Thomas BARTLETT, "Defenders and Defenderism in 1795 ", Irish Historical Studies, vol. XXIV, n 95 , May 1985, p. 373-394.

92. Vincent MORLEY, «The Continuity of Disaffection in Eighteenth-Century Ireland », art. cit.

93. Thomas BARTLETT, « Napoléon and Ireland », article à paraître. Je remercie Thomas Bartlett de m'avoir permis de lire cet article dans lequel il montre que l'imaginaire populaire irlandais a été durablement marqué par l'idée de secours venus de France, au point, ajoute-t-il non sans humour, de se demander si Napoléon n'était pas lui aussi en esprit dans le General Post Office en 1916 dans la référence aux « gallant allies in Europe ». 
94. Marianne elliott, Partners in Revolution, op. cit., p. 16 et 42.

95. Nancy CURTIN, United Irishmen, op. cit., p. 159.

96. Jim SMYTH, The Men of No Property, op. cit., p. 183.

97. Thomas O'Connor, An Irish Theologian in Enlightenment France, Luke Joseph Hooke, 1714-96, Dublin, Four Courts Press, 1995.

98. Dáire Keogh, The French Disease. The CatholicChurch and Irish Radicalism, 1790-1800, Dublin, Four Courts Press, 1993.

99. Kevin Whelan, "Politicisation in County Wexford and the Origins of the 1798 Rebellion ", dans Hugh Gough, David Dickson (dir.), Ireland and the French Revolution, op. cit., p. 156-178 ; Kevin WHELAN, "The Role of the Catholic Priest in the 1798 Rebellion in County Wexford ", dans Hugh Gough, David Dickson (dir.), Wexford: History and Society, Dublin, 1987, p. 296-315 ; Kevin WHELAN, "The Wexford Priests in 1798 », dans Liam swords (dir.), Protestant, Catholic \& Dissenter, op. cit., p. $165-185$.

100. Pour un exemple de ces passeurs liés au collège irlandais de Paris : Mathieu FERRADOU, « "La République au collège”, Paris, 29 octobre 1792 : catholicisme, radicalisme et républicanisme entre France et Irlande pendant la Révolution française (1792-1795) ", dans Karin Fischer, Clíona Ní Ríordáin (dir.), L'Irlande et sa république : passée, présente et à venir / Ireland's Republic : Past, Present and Future, Etudes irlandaises, vol. 41, n² , automne-hiver 2016, p. 119-133.

101. Louis M. CULLEN, «Late-Eighteenth Century Politicisation in Ireland: Problems in its Study and its French Links ", dans Culture et pratiques politiques en France et en Irlande, XVI ${ }^{e}-X V I I I^{e}$ siècle, Actes du colloque de Marseille, 28 septembre-2 octobre 1988, Paris, Publications du CRH, 1991, p. 137-157; Louis M. CuLLEN, "The Political Structures of the Defenders ", dans Hugh Gough, David Dickson (dir.), Ireland and the French Revolution, op. cit., p. 117-138.

102. Jim Sмyth, The Men of No Property, op. cit., p. 71.

103. Thomas BARTLETT, «An End to Moral Economy », art. cit., p. 44.

104. Tim MURTAGH, «Hibernian Sans-Culottes: Dublin's Artisans and the French Revolution, 1790-1798 ", La Révolution française [En ligne], 11|2016. URL: http://lrf.revues.org/citer ce numéro.

105. Nicholas A. M. ROGERS, "Mutiny or Subversion? Spithead and the Nore », dans Thomas Bartlett, David Dickson, Dáire Keogh, Kevin Whelan (dir.), 1798, A Bicentenary Perspective, op. cit., p. 549-564; Ann Veronica coats and Philip macdougall, The Naval Mutinies of 1797. Unity and Persverance, Woodbridge, The Boydell Press, 2011.

106. Pour une exploration de ces connexions : Niklas FRYKMAN, «Connections between Mutinies in European Navies », International Review of Social History, 58, 2013, p. 87-107.

107. Voir Niklas FRYKMAN, «The Wooden World Turned Upside Down: Naval Mutinies in the Age of Atlantic Revolution », thèse de doctorat, Université de Pittsburgh, 2010, à paraitre sous le titre The Marine Republic: Maritime Radicalism and the Revolutionary Atlantic, 1789-1805.

108. L'idée du bain de sang planifié par les catholiques pour mettre fin au "Cromwellian settlement » en Irlande est avancée par Samuel Turner, un membre du directoire national des Irlandais Unis, comme justification de son choix, lorsqu'il passe à l'ennemi et offre d'informer le gouvernement britannique depuis Hambourg: Christopher J. Woods, «Samuel Turner's Information on the United Irishmen, 1797-1798 », Analecta Hibernica, n 42 , 2011, p. 181-227. Sur les intentions de la France à l'égard d'une Irlande indépendante, voir les contributions de Hugh Gough et Tom Dunne dans John A. MURPHY (dir.), The French are in the Bay: the Expedition to Bantry Bay, 1796, Cork, Irish Amer Book, 1998, p. 73-84. L'idée d'échanger l'Irlande contre une colonie des Antilles a été d'abord exprimée par Denis Taafe (1759-1813), un prêtre catholique ayant fait ses études sur le Continent, converti au protestantisme une fois rentré à Dublin où il sombra dans la misère (Kevin WHELAN, "Introduction to Section VII ", dans Thomas Bartlett, David Dickson, Dáire Keogh, Kevin Whelan (dir.), 1798, A Bicentenary Perspective, op. cit., p. 529). 
109. Brendan SimmS, "Continental analogies with 1798: Revolution or Counter-Revolution?", dans Thomas Bartlett, David Dickson, Dáire Keogh, Kevin Whelan (dir.), 1798, A Bicentenary Perspective, op. cit., p. 577-595. Tom DUNNE, «Popular Ballads, Revolutionary Rhetoric and Politicisation ", dans Hugh Gough, David Dickson (dir.), Ireland and the French Revolution, op. cit., p. 139-155, dans une approche inspirée des subaltern studies voit également une similitude entre les Vendéens et les Defenders.

110. Un exemple, parmi d'autres, est donné avec Bartholomew Teeling, proche des Defenders : Christopher J. woods, "A Gallant, Intrepid, Unfortunate Officer : Bartholomew Teeling ", dans Sheila Mulloy, Victory or Glorious Defeat: Biographies of Participants in the Mayo Rebellion of 1798, Wesport, Carrowbaun Press, 2010, p. 163-193. Je remercie le Professeur David Dickson de m'avoir signalé cet article.

111. L'analyse classique de ces négociations se trouve chez Marianne ELliotT, Partners in Revolution, op. cit., p. 77-240.

112. Voir Sylvie KLEINMAN, "Rhétorique et mémoire de la souveraineté nationale irlandaise : Théobald Wolfe Tone et la République française, 1796-1798 », La Révolution française [En ligne], 11 | 2016. URL : http://lrf.revues.org/citer ce numéro.

113. Instructions du Directoire au général Humbert, $1^{\mathrm{er}}$ thermidor an VI (19 juillet 1798), SHD BB 123 fo 164-168. Une proclamation aux Irlandais signée James Napper Tandy est ainsi formulée : «nous jurons le respect le plus inviolable envers vos propriétés, vos lois et vos opinions religieuses. Soyez libres, soyez les maitres de votre propre pays. Nous ne cherchons aucune conquête sauf celle de votre Liberté, aucun succès si ce n'est le vôtre » (National Archives, Kew, PC 1/44/155).

114. En préambule de son cours sur la Révolution irlandaise à l'University College Dublin, Michael Laffan disait que la révolution sociale était terminée au début du XX $\mathrm{XX}^{\mathrm{e}}$ siècle avant que la révolution politique ne commence (http://historyhub.ie/theirishrevolution).

115. Thomas BARTLETT, Ireland. A History, op. cit., p. 363-371.

116. History Ireland, vol. 24, n³, May-June 2016.

117. Raymonde MONNIER, Républicanisme, patriotisme et Révolution française, Paris, L'Harmattan, 2005, p. 84 .

118. «Renverser la tyrannie de notre exécrable gouvernement, rompre le lien avec l'Angleterre, la source inépuisable de tous nos maux politiques, et affirmer l'indépendance de mon pays - tels étaient mes objectifs. Unir l'ensemble du peuple d'Irlande, abolir la mémoire de toutes les dissensions passées, et substituer le nom partagé d'Irlandais aux dénominations de protestants, catholiques et dissidents - tels étaient mes moyens »: The Writings of Theobald Wolfe Tone, vol. II, op. cit., p. 301.

119. Reinhard KOSSELECK, Le Futur passé. Contribution à la sémantique des temps historiques, Paris, éditions de l'EHESS, 1990, p. 307 et suivantes. Je remercie Jean-Clément Martin et Niklas Frykman pour les échanges autour de ces notions de révolte et guerre civile, d'anti- et de contrerévolution.

\section{RÉSUMÉS}

Cette introduction cherche à dresser un bilan historiographique sur le premier républicanisme irlandais afin de souligner dans quelle optique se situaient les contributions à la journée d'étude 
organisée sur ce thème à l'IHRF en mai 2016, ici présentées. Pour cela, elle pose d'emblée la question des écrans mémoriels et historiographiques qui, s'ils associent les origines du républicanisme irlandais à la France révolutionnaire, ont, depuis les $\mathrm{XIX}^{\mathrm{e}}$ et XX $\mathrm{XX}^{\mathrm{e}}$ siècles, chargé ce mot d'une connotation nationaliste, elle-même associée à la lutte armée et au catholicisme. Remonter à la période de l'Atlantique des révolutions a permis d'analyser l'émergence du républicanisme irlandais dans ses synergies avec l'Amérique et la France, et ainsi de mieux comprendre comment les multiples mécontentements et aspirations de la fin du XVIII siècle se sont cristallisés pour dessiner un horizon d'attente appelé République et qui, s'il était effectivement synonyme de nationalisme, signifiait alors indépendance et souveraineté populaire, c'est-à-dire liberté.

This introductory article has a twofold purpose: it first outlines the current state of the historiography on the early Irish republicanism; it then underlines the new approaches of the papers presented at the conference organised at the IHRF in May 2016, and available now. To achieve this purpose, this introduction starts with an examination of the memory and historiography of the Irish republicanism that emerged in the 1790s. Associated with revolutionary France, it has then been claimed by nationalist movements throughout the $19^{\text {th }}$ and $20^{\text {th }}$ centuries. Hence, it was associated with armed struggle and Catholicism. Going back to the period of the Atlantic Revolutions, the different contributions presented here analyse the emergence of Irish republicanism in its synergies with America and France, shedding new light on how the different strands of discontentment and multiple aspirations at the end of the $18^{\text {th }}$ century crystallised into a horizon of expectation called the Republic, which was indeed synonymous with nationalism, though it then meant independence and popular sovereignty, i.e. liberty.

\section{INDEX}

Mots-clés : République atlantique, Irlande, France, républicanisme, Révolution

Keywords : Atlantic Republic, Ireland, France, republicanism, Revolution 